\title{
When in life does density dependence occur in fish populations?
}

\author{
Andersen, Ken Haste; Jacobsen, Nis Sand; Jansen, Teunis; Beyer, Jan E
}

Published in:

Fish and Fisheries

Link to article, DOI:

$10.1111 /$ faf. 12195

Publication date:

2017

Document Version

Peer reviewed version

Link back to DTU Orbit

Citation (APA):

Andersen, K. H., Jacobsen, N. S., Jansen, T., \& Beyer, J. E. (2017). When in life does density dependence occur in fish populations? Fish and Fisheries, 18(4), 656-667. https://doi.org/10.1111/faf.12195

\section{General rights}

Copyright and moral rights for the publications made accessible in the public portal are retained by the authors and/or other copyright owners and it is a condition of accessing publications that users recognise and abide by the legal requirements associated with these rights.

- Users may download and print one copy of any publication from the public portal for the purpose of private study or research.

- You may not further distribute the material or use it for any profit-making activity or commercial gain

- You may freely distribute the URL identifying the publication in the public portal

If you believe that this document breaches copyright please contact us providing details, and we will remove access to the work immediately and investigate your claim 


\title{
When in life does density dependence occur in fish populations?
}

Running head: Density dependent regulation in fish

Ken H. Andersen ${ }^{1 *}$, Nis S. Jacobsen ${ }^{1}$, Teunis Jansen ${ }^{1,2}$ and Jan E. Beyer ${ }^{1}$

${ }^{1}$ Center for Ocean Life, National Institute of Aquatic Resources (DTU-Aqua), Technical University of Denmark, Charlottenlund Castle, DK-2920, Charlottenlund, Denmark

${ }^{2}$ Greenland Institute of Natural Resources, Nuuk, Greenland

*Correspondence to: kha@aqua.dtu.dk

\begin{abstract}
:
Fisheries advice is based on demographic calculations, which assume that density dependent processes regulating recruitment occur only in early life. This assumption is challenged by laboratory and lake studies and some recent indications from marine systems that demonstrate density dependent regulation late in life. By accounting for spatial dynamics of a population, something that has previously been ignored in models of fish, we show that density dependent regulation is determined by the size of the habitat: in small habitats, e.g. small lakes, regulation occurs late in life while it can occur early in large habitats. When regulation happens late in life, fisheries yield is maximized by exploitation of mainly juvenile fish, while exploiting mature fish maximizes yield if regulation happens early. We review and interpret observations of density dependence in light of the theory. Our results challenge the current assumption that density dependence always occurs early in life and highlights the need for an increased understanding of density dependent processes. This can only come about by a change of focus from determining stock-recruitment relationships towards understanding when and how density dependent regulation occurs in nature.
\end{abstract}

Key words: Maximum sustainable yield, selective fishing, spatial population dynamics 
"What checks the natural tendency of each species to increase in numbers is most obscure" Charles Darwin, Origin of Species

\section{Introduction}

The abundances of natural populations of plants and animals are regulated through changes in vital rates, such as growth and mortality, as the population density increases (reviewed by Rose and Cowan 2001). Examples of such density dependent regulation are reduced growth rates as the population increases (Svedäng and Hornborg 2014), lower reproductive output, range expansion (MacCall 1990), or increased mortality (van der Veer 1986), either due to risk-taking to compensate for a grazed-down resource, from behavioural changes in predators or, more commonly, from cannibalism (Smith and Reay 1991). Common for all types of density dependence is that they affect the survival between life stages.

Among marine fish density dependent regulation is thought to occur chiefly between hatching and age at recruitment and is usually modelled with a stock-recruitment curve relating the number of recruits to adult biomass (Beverton and Holt 1957; Myers and Cadigan 1993). The assumption of early density dependent regulation is often made implicitly and, if it is made explicitly, it is rarely specified when in life exactly density dependence is supposed to occur or by which process ("early" here means before fishing and before maturation). Further, there is no theoretical description of why density dependence should occur early in life, and not late. Despite the lack of theoretical support, there is a strong belief in these models (Froese et al 2015). This belief is challenged by empirical evidence of densitydependent growth (Lorenzen and Enberg 2002) putting the entire Beverton-Holt framework with its reliance on fixed growth, mortality and reproductive rates, into question (Lorenzen 2008; Persson et al. 2014). In multi-species models, such as size-spectrum models (Andersen et al. 2016) or Atlantis (Fulton et al. 2011), density dependence is modelled with a combination of a stock-recruitment relationship, resource competition and cannibalism. However, the relative strength of these processes has not been investigated, and the importance of density dependence on the results of such models is unknown. Empirical studies on density dependence in fish stocks almost exclusively focus on estimating stockrecruitment relationship and rarely address other types of density dependence. This lack of focus in theoretical and empirical works on when and how density dependence occurs means that we have little knowledge about how different types of density-dependent control may affect the validity of theoretical results on fisheries reference points, fisheries induced evolution, ecosystem effects of fishing, or the effects of size-selective fishing.

While models of marine fish populations rely on the assumption of early density dependence, models of fish populations in lakes avoid assumptions about when density dependence occurs and instead let density dependence emerge from resource competition or cannibalism (de Roos and Persson 2001; Persson et al. 2014). In such physiologically structured models density dependence often emerges late in life confirming observations (Post et al. 1999) of stunted growth (Ylikarjula et al. 1999) and "overcompensation" (de Roos and Persson 2002) whereby adult biomass is increased by selectively removing juveniles. The different descriptions of fish population dynamics in lakes and marine systems, and their fundamentally different conclusions about density dependence are yet to be reconciled.

Our aim is to critically evaluate the assumption about early density dependence in fish stocks and develop a theoretical understanding of which processes lead to early vs. late density 
dependence. An understanding of the difference between lakes and marine systems is reached by attention to the spatial dynamics of fish populations. We bring this understanding about by analysing a size-structured model where density dependent regulation is emergent and not prescribed, and show which conditions lead to emergent early vs. late density dependence.

We illustrate the importance of density dependent regulation by revisiting the problem of fisheries selectivity and yield maximisation in a single stock. Classic models based on stockrecruitment relationships predict that avoiding fisheries on juveniles maximises fisheries yield (Beverton and Holt 1957). These results are challenged by size spectrum model studies (Law et al. 2012, 2016), where density dependence is not prescribed by stock recruitment relationships, showing that yield is maximized when juveniles are fished, with the potential consequence that current selectivity practices are directly counterproductive (Svedäng and Hornborg 2014). Such conclusions are controversial because they challenge established beliefs (Froese et al. 2015). Here we show that the key to understand the differences between results from classic demographic models and size spectrum models is attention to density dependent effects: if density dependence is assumed to occur early, e.g. by a stockrecruitment relation, yield is maximized by fishing mature fish, while if density dependence emerges late, yield is maximized by fishing juveniles.

\section{Materials \& Methods}

The body size where density dependence regulation occurs has been described by a simple argument that relates intraspecific competition to the biomass of a cohort (Munch et al. 2005; Jennings et al. 2007). In the following we refine that argument by relating intraspecific competition to the interspecific competition with individuals from other species. Individuals compete with other individuals of a similar size. The range of sizes that compete is determined by the width of the prey size preference, which is proportional to the predators size (Ursin 1973). Consequently, an individual will compete for food with other individuals within a size-range proportional to its own size. The ratio of intra- to inter-specific competition can therefore be gauged by ratio between the biomass in the population and the biomass in the entire community within a size group proportional to body size: the higher the ratio, the stronger the intraspecific density dependent competition.

The biomass $B(w)$ of a size group of average body weight $w$ in a population can be calculated from the number size distribution. The number distribution of individuals in a population is given by the growth rate $g(w)$ and mortality $\mu(w)$ as (Andersen and Beyer 2015):

$$
N(w) \propto \frac{1}{g(w)} \exp \left[-\int_{w_{0}}^{w} \frac{\mu(\omega)}{g(\omega)} \mathrm{d} \omega\right]
$$

Multiplying $N(w)$ by the weight gives the biomass distribution, and multiplying once more by the weight gives the total biomass in a size group spanning a size range proportional to the size: $B(w) \propto N(w) w^{2}$. Using basic metabolic scaling relations for growth $g(w)=A w^{3 / 4}$ and mortality $\mu(w)=\alpha_{p} w^{-1 / 4}$, where $A$ and $\alpha_{p}$ are constants, gives:

$$
B(w) \propto w^{5 / 4-a},
$$


where $a=\alpha_{p} / A \approx 0.35$ (Andersen and Beyer 2015). Thus, the biomass of a size group in a population increases throughout life roughly as $w^{0.9}$, until around the size at maturation where growth slows down as the individuals approach their asymptotic size.

The biomass of the entire community within size groups proportional to body weight is roughly independent of size (Sheldon et al. 1977; Andersen and Beyer 2006). Since the community biomass is independent of size, the ratio between the biomass in the community and the population is $\propto B(w) \propto w^{0.9}$. This means that intraspecific competition for food increases with body size (Fig. 1, solid line), with a maximum competition around size at maturation where growth slows down. The argument therefore predicts that density dependent competition occurs late in life. This result is clearly at odds with the description of density dependence early in life by a stock recruitment relationship.

The simple argument developed above assumes that population dynamics is spatially homogeneous, i.e., that different life stages occupy the same area. However, the area that a size group occupies expands as the individuals grow in size (Fig. 2; Appendix B). We can describe the fraction $A(w)$ of the total habitat that a size group occupies as a power law function limited to occupy the entire habitat $(A(w) \leq 1)$ :

$$
A(w)= \begin{cases}\left(w / w_{+}\right)^{s} & \text { for } w<w_{+} \\ 1 & \text { for } w \geq w_{+}\end{cases}
$$

The exponent $s$ represents the speed of dispersal and the denominator $w_{+}$is the body size where the group has expanded to fill its entire habitat. We use the size $w_{+}$to characterize the size of the habitat. Empiric evidence (Appendix B), though inconclusive, as well as theoretical considerations (Appendix $\mathrm{C}$ ), indicate an exponent of dispersal $s \approx 1$.

We can incorporate dispersal (Eq. 1) in the argument developed above. Individuals of size $w$ occupy a habitat of size $A(w)$. Therefore their local biomass density increases by a factor $1 / A(w)$ and becomes $\propto w^{0.9-s}$ until the size where they fill the entire habitat at $w=w_{+}$at which point the density is $\propto w^{0.9}$ as before. The strength of interspecific competition becomes $\max \left(1,\left(w / w_{+}\right)^{-s}\right) w^{0.9}$, which for $s>0.9$ has two maxima: one very early in life and one late in life (Fig 1, dashed lines). Which of the two maxima dominates is determined by the size of the habitat $w_{+}$and the asymptotic size of the species. The early-life maximum will dominate for small species in large habitats while the late life maximum will dominate in small habitats or possibly also for large species in larger habitats.

To explore the simple argument developed above in more detail we modify an existing physiologically structured model of a fish population (Hartvig et al. 2011) to include a description of spatial dynamics (see Appendix A for equations and parameters). The model represents a fish population embedded in an ecosystem. The model is dynamic, massbalanced, based on individual level assumptions only, and features food-dependent growth rates of individuals, reproduction and cannibalistic mortality. We use the trait asymptotic size $W_{\infty}$ to represent the variation between species (Andersen and Beyer 2015). The output of a simulation is the number distribution $N(w)$, where $N(w) d w$ is the number of individuals in the body size (mass) range $[w: w+\mathrm{d} w]$. We represent the size distribution by $N(w) w^{2}$, which, as argued above, is proportional to the biomass in size groups evenly distributed on a logarithmic scale (Andersen et al. 2016) (Fig 1a). 
Individuals in the population feed on a resource size spectrum that represents prey (other fish and zooplankton) for the modelled population. The resource is modelled as a Sheldon spectrum (Sheldon et al. 1977) where biomass is roughly independent of body size. The resource is further characterized by a productivity scaling with body mass $w$ as $r_{0} w^{n-1}$ with $n=3 / 4$ being the metabolic exponent (Brown et al. 2004) and $r_{0}$ a free parameter that describes overall productivity. Predation occurs through the rule that bigger individuals eats smaller individuals (Ursin 1973; Cohen et al. 1993; Jennings et al. 2001). Reduction of the resource by the fish population results in reduced growth rates which leads to intraspecific density dependent competition. Size-dependent predation also leads to cannibalism. The body sizes at which density dependent competition and cannibalism occur are emergent results of the model.

\section{Results}

The model is constructed such that if growth and mortality are fixed, i.e., not determined by available food or cannibalism, it corresponds exactly to a classic demographic model used in fisheries research where density dependence is described by a stock-recruitment relationship (Andersen and Beyer 2015). Comparing growth and mortality between the stock-recruitment model and the one with emergent density dependence reveals when and how density dependent regulation emerges. Density dependent changes in growth are observed from the feeding level:

$$
f(w)=\frac{C(w)}{h w^{n}}
$$

which is the ratio between consumption $C(w)$ and maximum consumption $h w^{n}$ with $n=$ $3 / 4$ and $h$ being a constant. The feeding level is a non-dimensional number in the range 0 to 1. In the stock-recruitment model, the feeding level is independent of body size: $f(w)=$ $f_{0}=0.6$. In the example in Fig. 1c, density dependent reduction in growth is observed for the body sizes where $f(w)<f_{0}$, around $w=200 \mathrm{~g}$. Similarly, density dependent changes in mortality by cannibalism are observed as increases in mortality $\mu(w)$ compared to the stockrecruitment model (Fig. 1b). Mortality is described similar to the feeding level as a nondimensional number $l(w)$ which is the mortality relative to specific maximum consumption rate:

$$
l(w)=\frac{\mu(w) w}{h w^{n}} .
$$

In the absence of cannibalism $l(w)=l_{0}=0.084$. Density dependent cannibalism is observed for the body sizes where $l(w)>l_{0}$; around $w=3 \mathrm{~g}$ in Fig. $1 \mathrm{c}$.

The model simulations confirm the results of the simple argument: in small habitats such as lakes $\left(w_{+} \ll\right.$ the asymptotic size $\left.W_{\infty}\right)$ density dependent regulation emerges late (around maturation), while in spatially extended habitats such as shelf seas $\left(w_{+} \approx W_{\infty}\right)$ it may occur either early or late, depending on the asymptotic size of the species (Fig. 3).

To examine the importance of density dependent regulation on fisheries selectivity we create four cases by juxtaposing early vs. late regulation (large vs. small habitats) with cases where density dependence is dominated by either competitive or cannibalistic regulation (Table 1 and Fig. 5). These cases are established by varying the resource productivity that determines the type of density dependence: low productivity leads to high competition for a depleted 
resource with density dependence manifested as growth changes; high productivity leads to lower competition but high cannibalistic density dependent mortality (Fig. A2). We compare results with the model where density dependence is described with a stock recruitment relationship. In that case density dependent regulation is not emergent but bound to happen early in life.

Subjecting the modelled populations to fishing with varying minimum landing size limits reveals differences between the stock-recruitment model and our model with emergent density dependence (Fig. 6 and A4). In the model with a stock recruitment relationship, fisheries yield is maximised when fishing retains only adults (large size limit). With emerging density dependence, in small habitats $\left(w_{+} \ll W_{\infty}\right)$, yield is maximised with small size limits that target juveniles as much as adults, regardless of the type of density dependence (competitive or cannibalistic) because regulation always occurs late in life. In such cases, fishing with the size limit predicted by stock-recruitment theory would result in a loss of yield between $20 \%$ and $40 \%$. In large habitats $\left(w_{+} \approx W_{\infty}\right)$, the results are reversed and become aligned with predictions from classic stock-recruitment theory: yield is maximised with a size limit that exempts juvenile from being caught.

The importance of density dependent regulation varies systematically between species depending on their asymptotic size (Fig. A2): larger asymptotic size requires stronger regulation to obtain a population in equilibrium (Andersen and Beyer 2015). This mechanism, together with the size where density dependence occurs, determines the size limits that maximize yield in different species (Fig. 7a). As a consequence of the relatively weaker density dependent regulation in small species, fishing small species (asymptotic size $<50 \mathrm{~g}$ ) will predominately give the highest yield when adults are targeted, regardless of the size of the habitat and on whether regulation is early or late in life. The size limit that maximizes yield from larger species depends on the type of density dependence. In the example in Fig. 7a the largest species will always give the maximum yield when juveniles are selectively targeted. This result depends on the habitat size; in larger habitats targeting adult individuals will maximize yield (Fig 7b). The type of selection pattern (trawl or "balanced"; Garcia et al. 2012) is of minor importance to the results (Appendix D).

\section{Discussion}

By accounting for the spatial dynamics of a size group we have provided a framework to understand when in life density dependence occurs. The framework delivers the missing theoretical justification for the use of a stock-recruitment relationship. We have shown that early density dependence emerges in spatially extended habitats. In small habitats or if all life stages of the population occupy the same area, density dependence will emerge late in life (around maturation). In large habitats density dependence may occur early, however, for large species, we predict the possibility of additional density dependent regulation also late in life. These results imply that density dependence may occur late for fish populations in lakes, leading to stunted growth, while it will occur predominantly early for marine fish stocks, however, for large species in medium sized habitats density dependence may additionally occur late.

The description of spatial dynamics is a simplification of the processes that occur in natural fish stocks. The description does not, for instance, represent limitations in habitats that may occur in settling stages of demersal species, such as flatfish (Le Pape and Bonhommeau 
2015). Despite this, the analysis of spatial spreading of plaice was well described by the power-law model in Eq. (1). The model therefore covers the general aspect of the difference in population dynamics in small and large habitats. A complete understanding of the population dynamics and density dependence of a specific fish stock requires that more detail about the stock in question, e.g. the presence of life history change such as settling, is explicitly resolved.

The general prediction of density dependence is in line with examples of observations of density dependent regulation in natural fish populations (Table 2): in small lakes stunted growth is frequently observed (Burrough and Kennedy 1979; Ylikarjula et al. 1999), in particular in the absence of large predators (Rask 1983). Early density dependence might lead to overcompensation whereby mortality on juvenile life stages results in increased biomass of adults (de Roos and Persson 2002), with the consequence that fishing juveniles will lead to an increased fisheries yield (Svedäng and Hornborg 2014). Overcompensation emerges from competition between juveniles and adults when juveniles are the superior competitor (de Roos et al. 2008), and typically leads to stunted growth. Overcompensation typically occurs in small lake systems in the absence of predators. The presence of predators, such as pike (Esox lucius, Esocidae), may release the population from density dependent competition and remove the stunting (Persson et al. 2005), in a mechanism similar to how fishing with a small mesh size maximise yield in the model simulations where density dependence emerges late.

Although density dependence is less investigated in marine stocks than in lakes, available evidence suggests a different picture than in lakes. Several marine fish populations have strong density dependent juvenile mortality (van der Veer 1986; Myers and Cadigan 1993) supporting the paradigm of early life density dependent regulation. Further, examples of stunted growth in large lakes or marine systems are rare. One recent exception is Eastern Baltic cod (Gadus morhua, Gadidae) where adult growth rates in recent years appear to have almost ceased (Van Leeuwen et al. 2008; Eero et al. 2012). The habitable area for cod in the Eastern Baltic is limited by low salinity and the appearance of late density dependence in such a medium sized system is in accordance with our model predictions. Even though stunted growth is rarely observed, some density dependent adult growth regulation is frequent (Lorenzen and Enberg 2002). Finally, cannibalism is widespread among fish (Smith and Reay 1991). For example, cannibalism by adult cod can remove up to $40 \%$ of a cohort (Neuenfeldt 2000; ICES 2011). The observations of cannibalism and adult density dependent growth are in accordance with our prediction of a late secondary density dependent bottleneck. Taken together, extant evidence points to density dependence in marine fish population being more complex than can be captured by models of spatially homogeneous population dynamics or by models based on stock-recruitment relationships.

Whether density dependent regulation occurs early or late has implications for the mesh size regulations that maximise yield. If density dependence occurs late, size limit regulations will compromise the aim to achieve maximum sustainable yield from a fishery. In such cases targeting only adults will not maximise yield. This situation is most likely to occur in small habitats, such as lakes, or possibly for large species in medium sized habitats $\left(w_{+}<W_{\infty}\right)$. It is an open question whether the observed density dependent changes in adult growth and cannibalism (Table 2) are sufficient to compromise the theory behind current mesh size regulations; this requires full life cycle analyses akin to those performed for roach (Rutilus rutilus, cyprinidae) and perch (Perca fluviatilis, percidae) in lakes. 
Our model reconciles opposing views from lake and marine systems of how density dependence operates. It shows that insights from models and experiments that ignore spatial dynamics (Persson et al. 2007; Van Leeuwen et al. 2008; Schröder et al. 2009; Law et al. 2016) may not apply to marine systems. However, we also show that the classic assumption of early regulation in marine systems may not be justified. This questions the general validity of the stock-recruitment models used to determine size limit regulations in fisheries and for contemporary advanced stock assessments (Hilborn and Walters 1992). The potential implication of these results for current mesh size regulations should motivate investigations into how and when density dependent regulation occurs in natural fish stocks. Such a research program would deviate from the historical focus on stock-recruitment relationships and, at least initially, abandon the paradigm that density dependent regulation happen exclusively early in life.

\section{Acknowledgements:}

We thank Uffe H. Thygesen for help with the diffusion argument, Martin Lindegren, Keith Brander and Thomas Kiørboe for comments on drafts, and Rob van Gemert for doublechecking the calculations. This study is part of the VKR Centre of Excellence: Ocean Life and the EU FP7 project BIOC3. 


\section{References:}

Andersen, K.H. and Beyer, J.E. (2006) Asymptotic size determines species abundance in the marine size spectrum. The American Naturalist 168, 54-61.

Andersen, K.H. and Beyer, J.E. (2015) Size structure, not metabolic scaling rules, determines fisheries reference points. Fish and Fisheries 16, 1-22.

Andersen, K.H., Jacobsen, N.S. and Farnsworth, K.D. (2016) The theoretical foundations for size spectrum models of fish communities. Canadian Journal of Fisheries and Aquatic Science.

Beverton, R.J.H. and Holt, S.J. (1957) On the dynamics of exploited fish populations. H.M. Stationery Off.

Brown, J.H., Gillooly, J.F., Allen, A.P., Savage, V.M. and West, G.B. (2004) Toward a metabolic theory of ecology. Ecology 85, 1771-1789.

Burrough, R.J. and Kennedy, C.R. (1979) The occurrence and natural alleviation of stunting in a population of roach, Rutilus rutilus L. Journal of Fish Biology 15, 93-110.

Casini, M., Kornilovs, G., Cardinale, M., et al. (2011) Spatial and temporal density dependence regulates the condition of central Baltic Sea clupeids: compelling evidence using an extensive international acoustic survey. Population Ecology 53, 511-523.

Cohen, J.E., Pimm, S.L., Yodzis, P. and Saldaña, J. (1993) Body sizes of animal predators and animal prey in food webs. Journal Animal Ecology 62, 67-78.

Eero, M. (2012) Reconstructing the population dynamics of sprat (Sprattus sprattus balticus) in the Baltic Sea in the 20th century. ICES Journal of Marine Science 69, 1010-1018.

Eero, M., Vinther, M., Haslob, H., Huwer, B., Casini, M., Storr-Paulsen, M. and Köster, F.W. (2012) Spatial management of marine resources can enhance the recovery of predators and avoid local depletion of forage fish. Conservation Letters 5, 486-492.

Elliott, J. (1989) Mechanisms responsible for population regulation in young migratory trout, Salmo trutta. I. The critical time for survival. The Journal of Animal Ecology 58, 9871001.

Froese, R., Walters, C., Pauly, D., et al. (2015) A critique of the balanced harvesting approach to fishing. ICES J. Mar. Sci.

Fulton, E.A., Link, J.S., Kaplan, I.C., et al. (2011) Lessons in modelling and management of marine ecosystems: The Atlantis experience. Fish and Fisheries 12, 171-188.

Garcia, S.M., Kolding, J., Rice, J., et al. (2012) Reconsidering the consequences of selective fisheries. Science 335, 1045-1047.

Graham, M. (1948) Reporter's review of the scientific meeting on the effect of the war on the stocks of commercial food fishes. In: Rapports et Procès-Verbaux des Réunions du Conseil International pour l'Exploration de la Mer. p 122: 6.

Hartvig, M., Andersen, K.H. and Beyer, J.E. (2011) Food web framework for size-structured populations. Journal of Theoretical Biology 272, 113-122.

Hilborn, R. and Walters, C.J. (1992) Quantitative Fisheries Stock Assessment: Choice, Dynamics and Uncertainty. Springer.

ICES (2014) Report of the Baltic Fisheries Assessment Working Group (WGBFAS).

ICES (2011) Report of the Working Group on Multispecies Assessment Methods (WGSAM), ICES CM 2011/SSGSUE:10. 
Jansen, T. and Burns, F. (2015) Density dependent growth changes through juvenile and early adult life of North East Atlantic Mackerel (Scomber scombrus). Fisheries Research 169, 37-44.

Jennings, S., Oliveira, J. and Warr, K.J. (2007) Measurement of body size and abundance in tests of macroecological and food web theory. Journal Animal Ecology 44, 72-82.

Jennings, S., Pinnegar, J.K., Polunin, N.V.C. and Boon, T.W. (2001) Weak cross-species relationships between body size and trophic level belie powerful size-based trophic structuring in fish communities. Journal Animal Ecology 70, 934-944.

Law, R., Plank, M.J. and Kolding, J. (2016) Balanced exploitation and coexistence of interacting, size-structured, fish species. Fish and Fisheries 17, 281-302.

Law, R., Plank, M.J. and Kolding, J. (2012) On balanced exploitation of marine ecosystems: results from dynamic size spectra. ICES Journal of Marine Science 69, 602-614.

Van Leeuwen, A., de Roos, A.M. and Persson, L. (2008) How cod shapes its world. Journal of Sea Research 60, 89-104.

Lorenzen, K. (2008) Fish population regulation beyond "stock and recruitment": the role of density-dependent growth in the recruited stock. Bulletin of Marine Science 83, 181196.

Lorenzen, K. and Enberg, K. (2002) Density-dependent growth as a key mechanism in the regulation of fish populations: evidence from among-population comparisons. Proceedings of the Royal Society of London B 269, 49-54.

MacCall, A.D. (1990) Dynamic geography of marine fish populations. University of Washington press.

Munch, S.B., Snover, M.L., Watters, G.M. and Mangel, M. (2005) A unified treatment of top-down and bottom-up control of reproduction in populations. Ecology Letters 8, 691695.

Myers, R. and Cadigan, N. (1993) Density-dependent juvenile mortality in marine demersal fish. Canadian Journal of Fisheries and Aquatic Science 50, 1576-1590.

Neuenfeldt, S. (2000) Trophodynamic control on recruitment success in Baltic cod: the influence of cannibalism. ICES Journal of Marine Science 57, 300-309.

Okamoto, D.K., Schmitt, R.J. and Holbrook, S.J. (2016) Stochastic density effects on adult fish survival and implications for population fluctuations. Ecology Letters 19, 153-162.

Olafsdottir, A., Slotte, A., Jacobsen, J., Oskarsson, G., Utne, K. and Nøttestad, L. (2016) Changes in weight-at-length and size-at-age of mature Northeast Atlantic mackerel (Scomber scombrus) from 1984 to 2013: effects of mackerel stock size and herring (Clupea harengus) stock size. ICES Journal of Marine Science 73, 1255-1265.

Le Pape, O. and Bonhommeau, S. (2015) The food limitation hypothesis for juvenile marine fish. Fish and Fisheries 16, 373-398.

Persson, L., Amundsen, P.-A., de Roos, A.M., Klementsen, A., Knudsen, R. and Primicerio, R. (2007) Culling prey promotes predator recovery - alternative states in a whole-lake experiment. Science 316, 1743-1746.

Persson, L., Dynamics, E. and Science, E. (2005) How prey change the size distribution of their predators and promote their own persistence.

Persson, L., van Leeuwen, A. and de Roos, A.M. (2014) The ecological foundation for ecosystem-based management of fisheries: mechanistic linkages between the individual- 
, population-, and community-level dynamics. ICES Journal of Marine Science 71, $2268-2280$.

Post, J.R., Parkinson, E.A. and Johnston, N.T. (1999) Density-dependent processes in structured fish populations: Interaction strengths in whole-lake experiments. Ecological Monographs 69, 155-175.

Rask, M. (1983) Differences in growth of perch (Perca fluviatilis L.) in two small forest lakes. Hydrobiologia 101, 139-144.

Rijnsdorp, A. and Leeuwen, P. Van (1992) Density-dependent and independent changes in somatic growth of female North Sea plaice Pleuronectes platessa between 1930 and 1985 as revealed by back-calculation of otoliths. Marine Ecology Progress Series 88, $19-32$.

de Roos, A.M. and Persson, L. (2001) Physiologically structured models - from versatile technique to ecological theory. Oikos 94, 51-71.

de Roos, A.M. and Persson, L. (2002) Size-dependent life-history traits promote catastrophic collapses of top predators. Proceedings of the National Academy of Science U.S.A. 99, 12907-12912.

de Roos, A.M., Schellekens, T., van Kooten, T., van de Wolfshaar, K., Claessen, D. and Persson, L. (2008) Simplifying a physiologically structured population model to a stagestructured biomass model. Theoretical Population Biology 73, 47-62.

Rose, K., Cowan, J., Winemiller, K.O., Myers, R. a and Hilborn, R. (2001) Compensatory density dependence in fish populations: importance, controversy, understanding and prognosis. Fish and Fisheries 2, 293-327.

Schröder, A., Persson, L. and de Roos, A.M. (2009) Culling experiments demonstrate sizeclass specific biomass increases with mortality. Proceedings of the National Academy of Sciences of the United States of America 106, 2671-6.

Sheldon, R.W., Sutcliffe Jr., W.H. and Paranjape, M.A. (1977) Structure of pelagic food chain and relationship between plankton and fish production. Journal Fisheries Research Board of Canada 34, 2344-2353.

Smith, C. and Reay, P. (1991) Cannibalism in teleost fish. Reviews in Fish Biology and Fisheries 1, 41-64.

Svedäng, H. and Hornborg, S. (2014) Selective fishing induces density-dependent growth. Nature communications $\mathbf{5}, 4152$.

Trenkel, V.M., Huse, G., MacKenzie, B.R., et al. (2014) Comparative ecology of widely distributed pelagic fish species in the North Atlantic: Implications for modelling climate and fisheries impacts. Progress in Oceanography 129, 219-243.

Ursin, E. (1973) On the prey size preferences of cod and dab. Meddelelser fra Danmarks Fiskeri- og Havundersøgelser 7, 85-98.

van der Veer, H. (1986) Immigration, settlement, and density-dependent mortality of a larval and early postlarval 0 -group plaice (Pleuronectes platessa) population in the western Wadden Sea. Marine Ecology Progress Series 29, 223-236.

Ylikarjula, J., Heino, M. and Dieckmann, U. (1999) Ecology and adaptation of stunted growth in fish. Evolutionary Ecology 13, 433-453. 
Table 1. Parameters used for the five cases; $W_{\infty}=1 \mathrm{~kg}$

\begin{tabular}{llc}
\hline Case & Resource productivity & Cohort spreading \\
\hline A. Density independent & Fixed resource $\left(r_{0}=\infty\right)$ & - \\
B. Late competitive & $r_{0}=0.1 \mathrm{~g}^{0.25} \mathrm{yr}^{-1}$ & - \\
C. Late cannibalistic & $r_{0}=10 \mathrm{~g}^{0.25} \mathrm{yr}^{-1}$ & - \\
D. Early competitive & $r_{0}=1 \mathrm{~g}^{0.25} \mathrm{yr}^{-1}$ & $s=1 ; w_{+}=100 \mathrm{~g}$ \\
E. Early cannibalistic & $r_{0}=100 \mathrm{~g}^{0.25} \mathrm{yr}^{-1}$ & $s=1 ; w_{+}=100 \mathrm{~g}$ \\
\hline
\end{tabular}

Table 2: Observations of density dependent regulation in natural and experimental fish populations, roughly ordered by size of system, from small to large.

\begin{tabular}{|c|c|c|c|}
\hline Species & System & Description & Refs. \\
\hline $\begin{array}{l}\text { Heterandria } \\
\text { formosa }\end{array}$ & Aquaria & $\begin{array}{l}\text { Overcompensation }=>\text { late competitive density } \\
\text { dependent regulation. }\end{array}$ & 1 \\
\hline $\begin{array}{l}\text { Brown trout } \\
\text { (Salmo trutta, } \\
\text { Salmonidae) }\end{array}$ & Stream & $\begin{array}{l}\text { Larval survival limited by spawning habitat => } \\
\text { early-life density dependent regulation. }\end{array}$ & 2 \\
\hline $\begin{array}{l}\text { Arctic charr } \\
\text { (Salvelinus } \\
\text { alpinus, } \\
\text { Salmonidae) }\end{array}$ & Small lake & $\begin{array}{l}\text { Overcompensation driven by predation; stunted } \\
\text { growth => late competitive density dependent } \\
\text { regulation. }\end{array}$ & 3. \\
\hline $\begin{array}{l}\text { Rainbow trout } \\
\text { (Oncorhynchus } \\
\text { mykiss, } \\
\text { Salmonidae) }\end{array}$ & Lakes & Late density dependent regulation & 4. \\
\hline $\begin{array}{l}\text { Perch (Perca } \\
\text { flavescens, } \\
\text { Perciformes), } \\
\text { roach (Rutilus, } \\
\text { rutilus, } \\
\text { Cyprinidae) }\end{array}$ & Lakes & $\begin{array}{l}\text { Stunted growth }=>\text { late competitive density } \\
\text { dependent regulation. }\end{array}$ & 5. \\
\hline $\begin{array}{l}\text { Herring (Clupea } \\
\text { harengus, } \\
\text { Clupeinae) }\end{array}$ & Fjords & $\begin{array}{l}\text { Density dependent adult growth in fjords, but not } \\
\text { in the sea at large. }\end{array}$ & 6. \\
\hline $\begin{array}{l}\text { Cod (Gadus } \\
\text { morhua, } \\
\text { Gadidae) }\end{array}$ & $\begin{array}{l}\text { Eastern } \\
\text { Baltic }\end{array}$ & $\begin{array}{l}\text { Low condition in last } 10 \text { years }=>\text { indicative of } \\
\text { stunted growth and late competitive density } \\
\text { dependent regulation. }\end{array}$ & 7. \\
\hline Cod & $\begin{array}{l}\text { Eastern } \\
\text { Baltic }\end{array}$ & $\begin{array}{l}\text { Strong cannibalism by adults }=>\text { some } \\
\text { cannibalistic late density dependent regulation. }\end{array}$ & 8. \\
\hline $\begin{array}{l}\text { Sprat (Sprattus, } \\
\text { sprattus, } \\
\text { Clupeidae) }\end{array}$ & $\begin{array}{l}\text { Eastern } \\
\text { Baltic }\end{array}$ & $\begin{array}{l}\text { Strong reduction in adult growth }=>\text { late density } \\
\text { dependent competition }\end{array}$ & 9. \\
\hline $\begin{array}{l}\text { Herring, sole } \\
\text { (Solea solea, } \\
\text { Soleidae), silver } \\
\text { hake } \\
\text { (Merluccius } \\
\text { bilinearis, } \\
\text { Merlucciinae) }\end{array}$ & Marine & $\begin{array}{l}\text { Adult density dependent growth => some late } \\
\text { density dependent competition. }\end{array}$ & 10. \\
\hline
\end{tabular}




\begin{tabular}{|c|c|c|c|}
\hline $\begin{array}{l}\text { Atlantic } \\
\text { mackerel } \\
\text { (Scomber } \\
\text { scombrus, } \\
\text { Scombrini) }\end{array}$ & $\begin{array}{l}\text { North East } \\
\text { Atlantic }\end{array}$ & $\begin{array}{l}\text { Density dependent growth in early and late life } \\
=>\text { density dependent competition throughout } \\
\text { life. }\end{array}$ & 11. \\
\hline $\begin{array}{l}\text { Plaice } \\
\text { (Pleuronectes } \\
\text { platessa, } \\
\text { Pleuronectidae) }\end{array}$ & North Sea & $\begin{array}{l}\text { Density dependent juvenile mortality and density } \\
\text { dependent adult growth => probably dominated } \\
\text { by early density-dependent regulation. }\end{array}$ & 12. \\
\hline $\begin{array}{l}\text { Cod, haddock } \\
\text { (Melanogramm } \\
\text { us aeglefinus, } \\
\text { Gadidae), } \\
\text { plaice, sole, } \\
\text { whiting } \\
\text { (Merlangius } \\
\text { merlangus, } \\
\text { Gadidae) }\end{array}$ & North Sea & $\begin{array}{l}\text { Density dependent survival, most prominently in } \\
\text { younger stages => early-life density dependent } \\
\text { regulation. }\end{array}$ & 13. \\
\hline Cod, Whiting & North Sea & Cannibalism & 14. \\
\hline Reef fish & Coral reefs & $\begin{array}{l}\text { Adult density-dependent survival }=>\text { late density } \\
\text { dependent regulation }\end{array}$ & 15. \\
\hline Several & Marine & $\begin{array}{l}\text { Some evidence of density-dependent growth } \\
\text { changes, but insufficient to explain all density } \\
\text { dependence. }\end{array}$ & 16. \\
\hline \multicolumn{4}{|c|}{$\begin{array}{l}\text { 1. Schröder et al. 2009; 2. Elliott 1989; 3. Persson et al. 2007; 4. Post et al. 1999; 5. Burrough and } \\
\text { Kennedy 1979; Rask 1983; 6. Trenkel et al. 2014; 7. Eero et al. 2012; ICES 2014; Svedäng and Hornborg } \\
\text { 2014; 8. Neuenfeldt 2000; 9. Casini et al. 2011; Eero 2012; 10. Lorenzen and Enberg 2002; 11. Jansen } \\
\text { and Burns and Olafsdottir et al. 2016; 12. van der Veer 1986; Rijnsdorp and Leeuwen 1992; 13. Myers } \\
\text { and Cadigan 1993. 14. ICES 2011, Figure 4.1.7; 15. Okamoto et al. 2016; 16. Graham 1948. }\end{array}$} \\
\hline
\end{tabular}




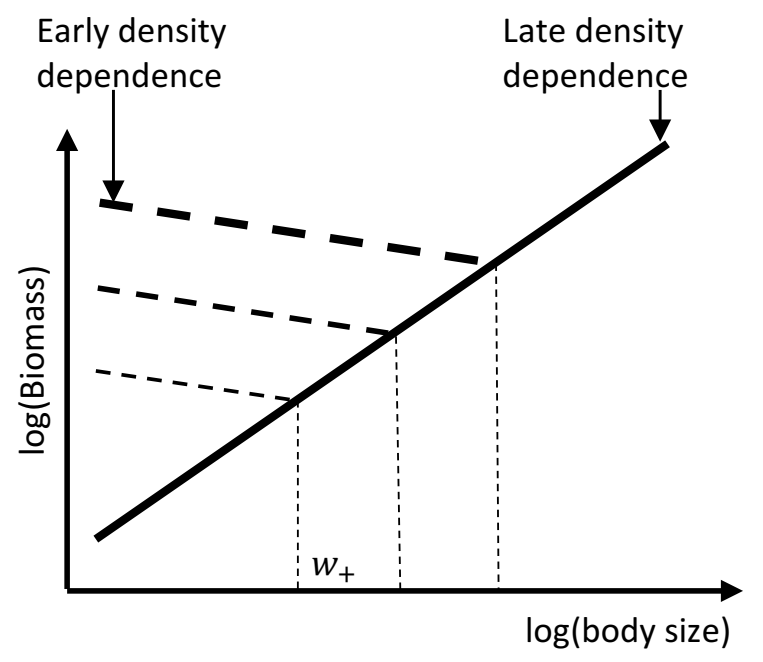

Figure 1. Biomass of a size group in a population as a function of body size. Solid line shows the biomass if the size group fills the entire habitat; dashed lines show the biomass density (biomass per area) in habitats of increasing size indicated by line width. Maxima in the biomass indicates sizes where intraspecific density dependence occur; see text for details. 


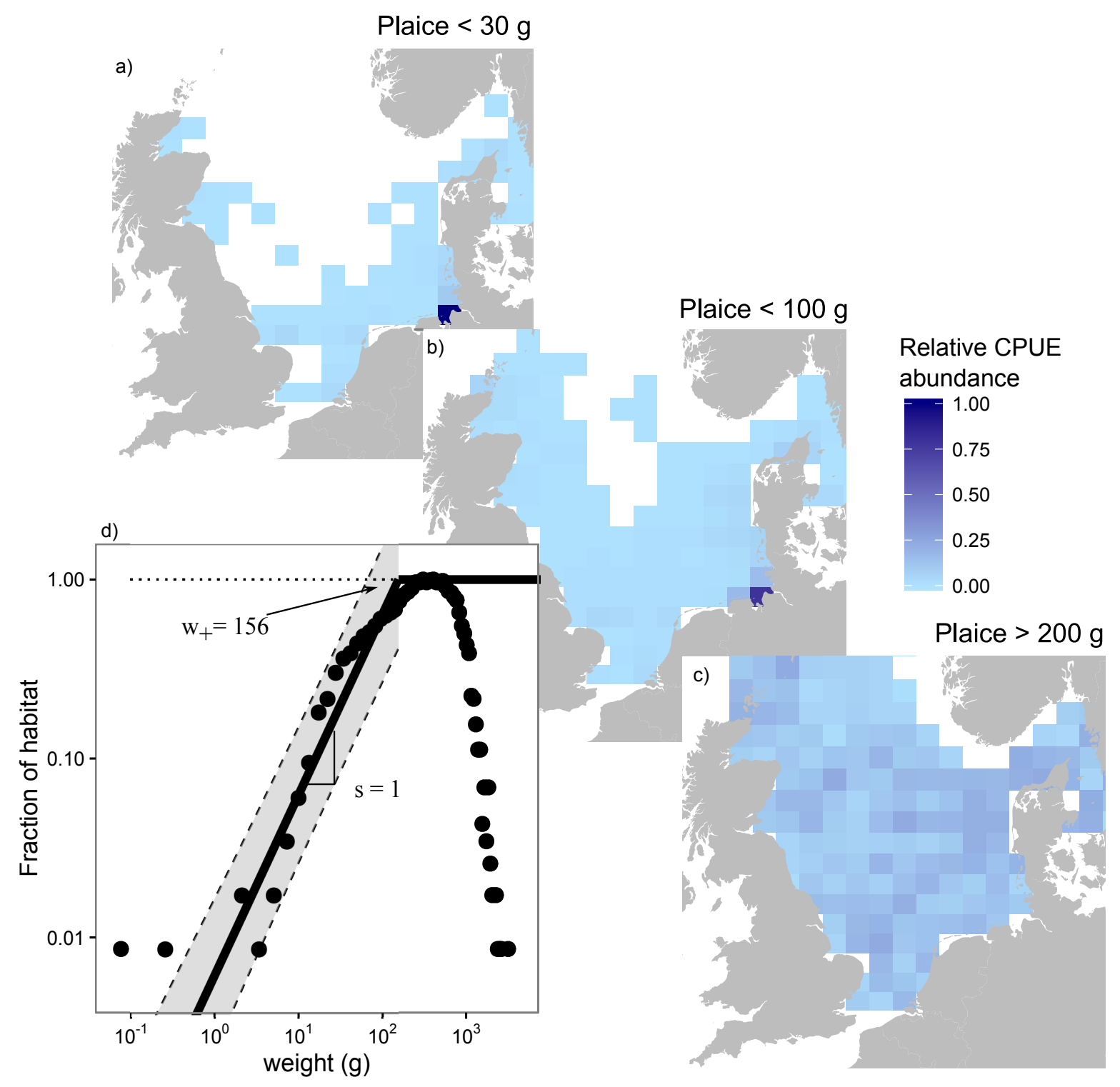

Figure 2. Dispersal of plaice (Pleuronectes platessa, Pleuronectidae) in the North Sea as a function of weight. a-c) Intensity of colours indicates relative abundance within each weight group. d) The fraction of the total area occupied by a size group as a function of size. The juveniles are concentrated in coastal areas, but spread out as they grow with exponent $s \approx 1$ to cover the entire area at a size $w_{+} \approx 156 \mathrm{~g}$ (black line). Depending on which points are included in the regression $s$ can be in the interval 1 to 1.3 and $w_{+} \approx 85-350 \mathrm{~g}$ (grey area). See Appendix B for details and further examples. 


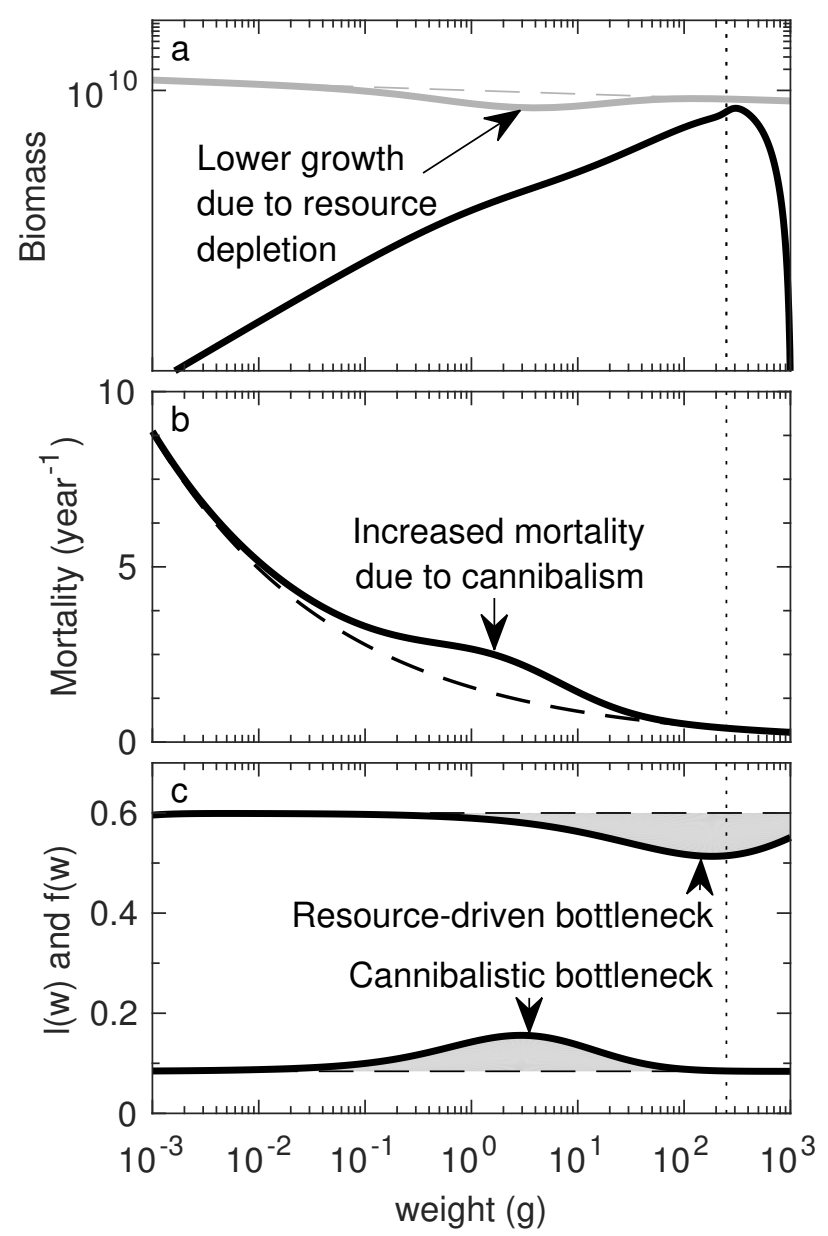

Figure 3. Simulation of a single population with asymptotic size $1 \mathrm{~kg}$ feeding on a community with productivity $r_{0}=2 \mathrm{yr}^{-1} \mathrm{~g}^{0.25}$. The central process is bigger individuals eating smaller prey; the preferred predator-prey size ratio is illustrated with the arrows on top. a) Black: biomass in logarithmic size groups. Grey: resource spectrum with the dashed line showing carrying capacity. b) Imposed natural mortality (dashed) and total mortality (natural + cannibalism) (solid). c) Density dependent effects (grey areas) shown as the difference between actual feeding level $\left(f(w)\right.$, solid) and density-independent feeding level $\left(f_{0}\right.$, upper dashed line), and as the difference between total scaled mortality $(l(w)$, solid $)$ and background mortality $\left(l_{0}\right.$, lower dashed). In this example the largest biomass of the population is at a size around $300 \mathrm{~g}$, which induces a reduction in resources around $3 \mathrm{~g}$, which leads to a reduction in growth around $200 \mathrm{~g}$. Predation further imposes a cannibalistic with a maximum around $3 \mathrm{~g}$. The vertical dotted line shows the size at maturation. 


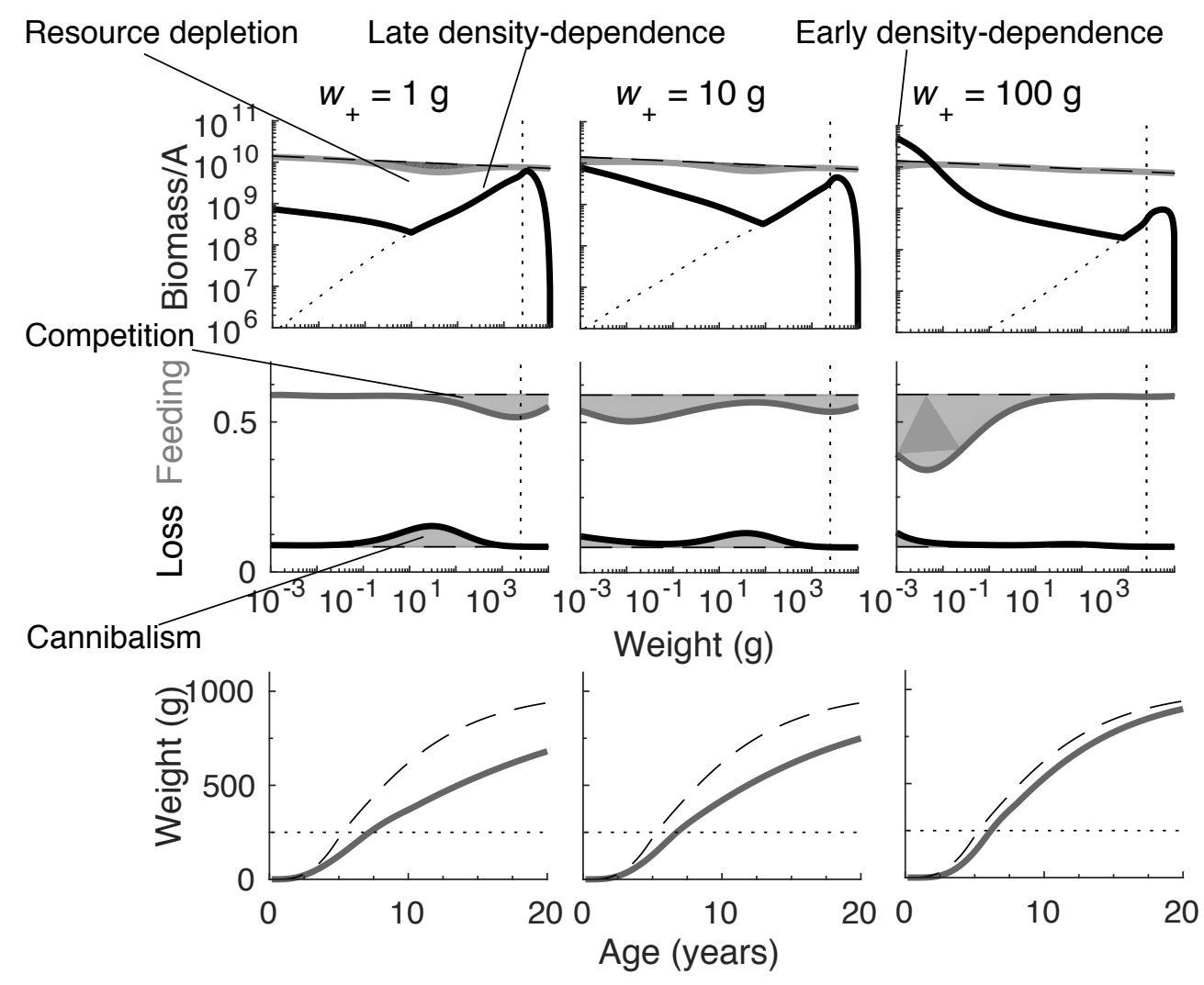

Figure 4. Population structure and emergent density dependent regulation of populations in habitats with increasing size $w_{+}$(from left to right). Top row: Biomass distributions of the population (black) and resource (grey). The thick black lines show the biomass density within the habitat occupied by individuals of a given size while the black dotted lines show the biomass in the entire habitat. Predation on the resource leads to depletion of the resource from its carrying capacity (dashed line). Middle row: Feeding level $f(w)$, i.e. the consumption divided by the maximum consumption (grey), and losses to mortality $l(w)$ (black). Bottom row: weight-at-age (solid) compared to density-independent weight-atage (dashed). In this example asymptotic size $W_{\infty}=1 \mathrm{~kg}$, size at maturation $250 \mathrm{~g}$ (dotted lines), resource productivity $r_{0}=5 \mathrm{yr}^{-1} \mathrm{~g}^{0.25}$, and exponent of spatial dispersal $s=1$. 

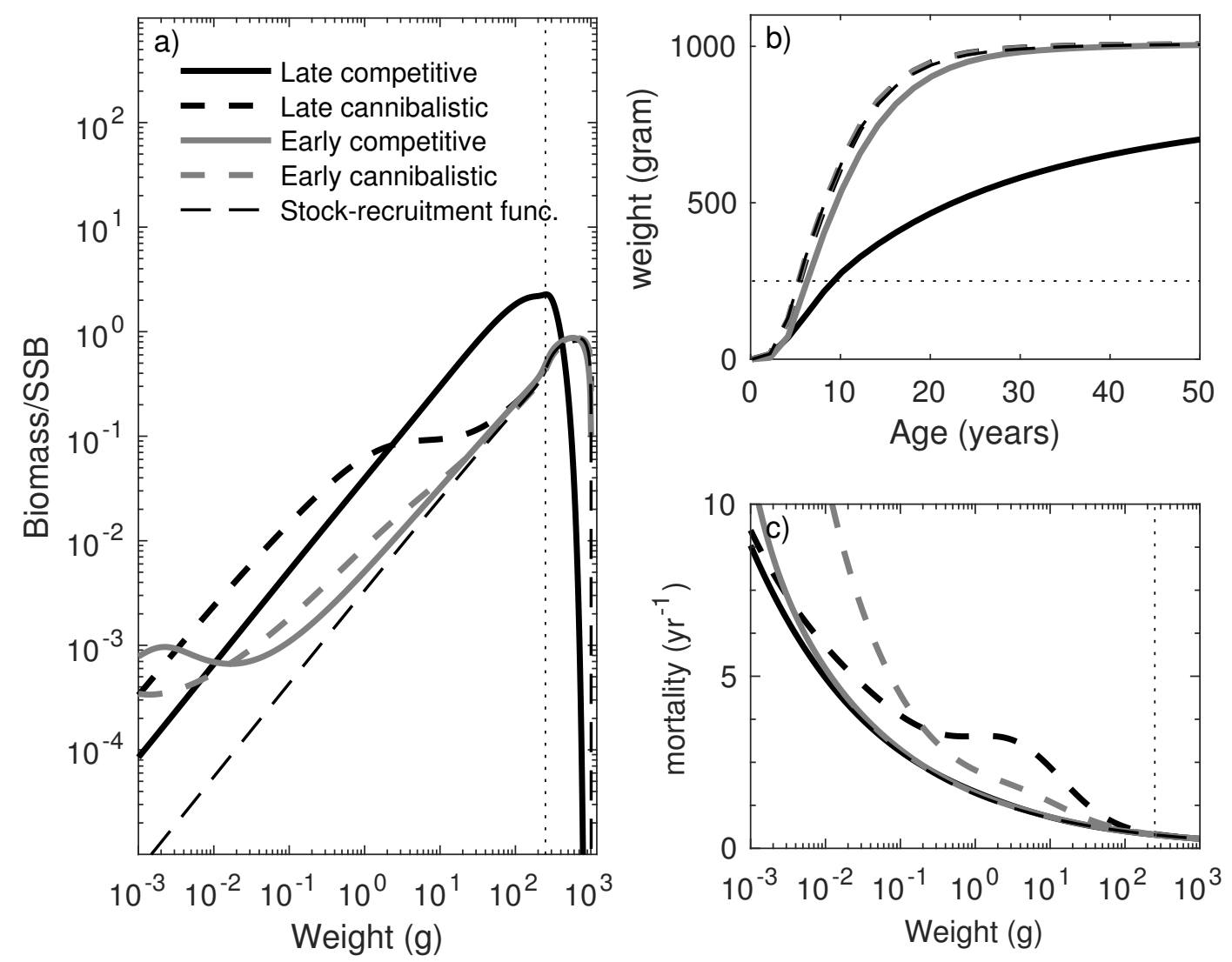

Figure 5. Biomass spectra and size-at-age for the five cases of density dependence described in table 2. Asymptotic size $1 \mathrm{~kg}$, no fishing and other parameters as in Table A2. a) Biomass spectra normalized by the total adult biomass ("spawning stock biomass"). The vertical dotted line denotes size at maturation. Notice that the adult spectra of all cases except the late resource-driven spectra are almost identical to the stock-recruitment based solution. b) Sizeat-age with the dotted line showing size at maturation. c) Imposed natural mortality (solid) and total mortality (natural + cannibalism) (dashed). 
Figure 6

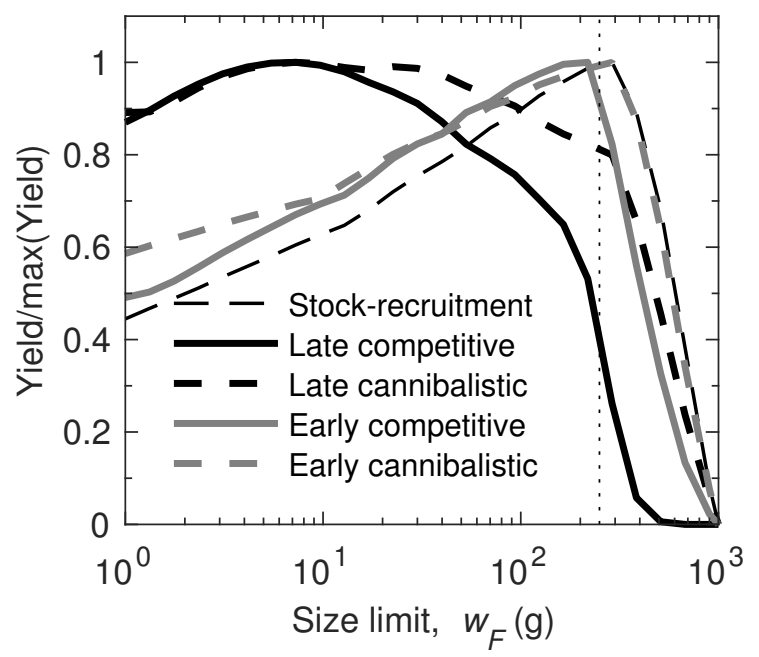

Figure 6. Fisheries yield vs. minimum landing size limit for four types of emergent density dependent regulation compared to stock-recruitment theory (black dashed). Yield is maximized with a size limit around size at maturation (dotted line) only when density dependent regulation occurs early. Parameters: asymptotic size $W_{\infty}=1 \mathrm{~kg}$ and Table S4.
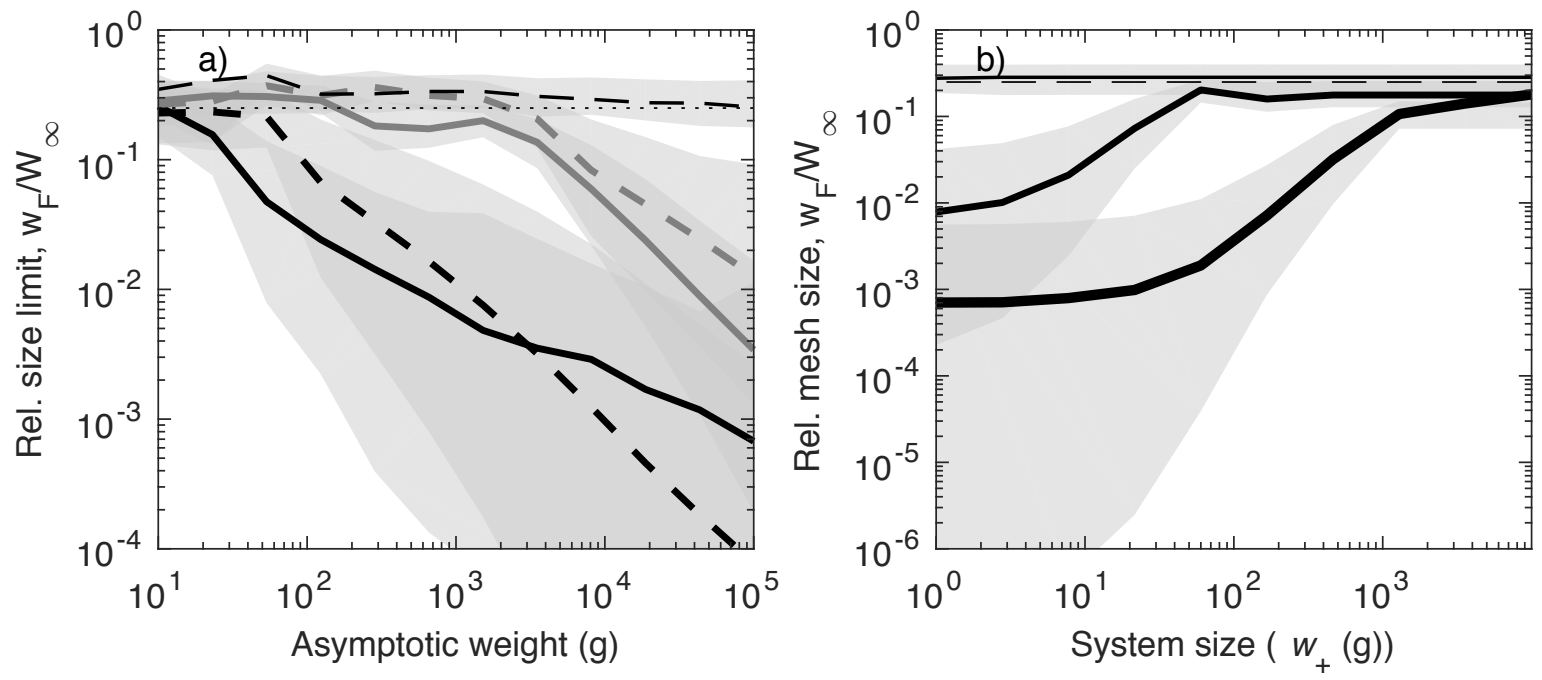

Figure 7. The minimum landing size limit $w_{F}$ (relative to the asymptotic size $W_{\infty}$ ) giving the maximum sustainable yield as a function of asymptotic size (a) and system size (b). Grey areas show the landing size limit giving $90 \%$ of the maximum yield. a: Size limit as a function of asymptotic size for the five case in Table 1. The dotted line shows the size at maturation. Line symbols and other parameters as in Figure 5, system size is $w_{+}=100 \mathrm{~g}$. See Fig. A1.4 and A1.5 for more details. b) Size limit as a function of system size $w_{+}$for three species with asymptotic size $10 \mathrm{~g}$ (thin line), $1000 \mathrm{~g}$ and $100 \mathrm{~kg}$ (thick line). 


\section{Appendices for "When in life does density dependence occur in fish populations?"}

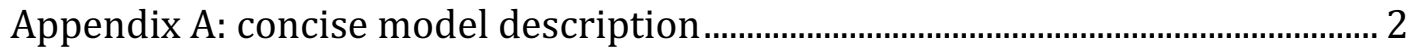

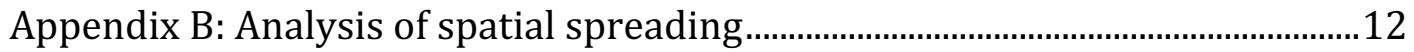

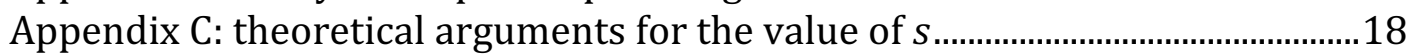

Appendix D: influence of size-selection pattern........................................................20

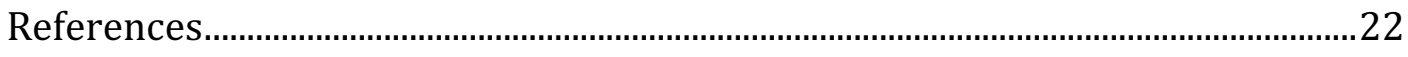




\section{Appendix A: concise model description}

The model is a single species version of the physiologically structured size-based multispecies model developed by Hartvig et al. (2011), updated with revised parameters and bioenergetics budget (Andersen and Beyer 2015) and spatial dispersion of a cohort (Eq. 1). The model is based entirely on individual-level processes and two central assumptions: $i$ ) bigger fish eat smaller fish and $i i$ ) the variation between species can be described by the trait asymptotic size, $W_{\infty}$. Governing equations are listed in Table A1 and parameters in Table A2.

The demography of individuals with body mass $w$ is described by the size spectrum $N(w)$ (dimensions numbers per mass). The size spectrum represents the number of individuals in the range $[w: w+\mathrm{d} w]$ as $N(w) \mathrm{d} w$ and the biomass as $N(w) w \mathrm{~d} w$. Considering a logarithmic scaling of size bins, i.e., where the width of each bin is proportional to the weight $d w \propto w$, the biomass in each bin is proportional to $N(w) w^{2}$ (Sheldon et al. 1972, Andersen and Beyer 2006). This representation of the size spectrum is used in the figures.

The model operates with two size spectra: the resource spectrum $N_{R}(w)$ and the size spectrum of the focal population $N(w)$. The size spectrum of the population is found by a solution of the McKendrick-von Foerster conservation equation:

$$
\frac{\partial N(w)}{\partial t}+\frac{\partial g(w) N(w)}{\partial w}=-\mu(w) N(w)
$$

where $g(w)$ is the growth rate (mass per time) and $\mu(w)$ is the mortality rate (per time).

The central process is the encounter between individuals. An individual encounters smaller individuals with a log-normal size preference (M1). It does not distinguish between whether the individuals are from the resource or conspecifics. The encountered amount of food (biomass per time) is thus determined by a combination of the total size spectrum $N_{R}(w)+N(w)$, the size preference and the clearance rate of the individual (M2). The actual consumption is limited by a functional response (M3) to represent the capacity of the digestive system (M4).

Consumed food is assimilated and used for standard metabolism and activity. The remainder is the available energy for growth or reproduction (M5). The available energy is divided between growth (M6) and reproduction (M7) by a function that switches to reproduction around the size at maturation (M8). The division of energy is constructed such that growth will be well approximated by a von Bertalanffy growth curve if consumption is a constant fraction of the maximum consumption, i.e., if the feeding level is constant (Hartvig et al. 2011, Eq. 9). The amount of energy diverted to reproduction is used as boundary condition for the conservation equation (M9a).

Mortality arises from three sources: a background predation mortality (M10), a cannibalistic predation mortality (M11) and fishing mortality (M12). The background mortality represents predation from the resource spectrum. This mortality is fixed for simplicity, hence depletion of the resource spectrum does not result in lower predation rates on smaller individuals. Fishing is acting on individuals larger than a minimum 
size $w_{F}$ and is either constant (trawl-type selectivity M12a) or declining with size (balanced selectivity M12b) (Fig. A1).

The resource spectrum extends through all sizes, with each size group modelled as a chemostat (M13) with carrying capacity (M14) and productivity (M15) scaling with size. The scaling of the carrying capacity is set such that feeding on the resource at carrying capacity will result in a constant feeding level $f(w)=f_{0}$ of the fish population (Hartvig et al. 2011, app. D).

The effect of spatial dispersal of the population as they grow in size is represented in the predation mortality (M11). This is captures most of the effects of spatial dispersal but it is not perfect: cannibalistic individuals that do not have an overlap with the prey also obtain food from cannibalism. This effect will overestimate the positive effect of cannibalism on growth. Fixing this problem would require making a spatially explicit model, which is beyond our capacity.

If growth and mortality are fixed, i.e., they are independent of available food or cannibalism, results correspond exactly to a classic demographic model used in fisheries research (Andersen and Beyer 2015). In that case density dependent regulation is not emergent but prescribed to occur early in life through a stockrecruitment relationship that modifies the boundary condition (M9b).

\section{Analysis of the model}

If the feeding level is constant $f_{0}$ and if cannibalistic mortality is ignored, we can construct an analytic prediction of the scaling of the size spectrum (Andersen and Beyer 2006). In that case growth is $g(w) \propto w^{n}$ and mortality is $\mu(w) \propto w^{n-1}$. The size spectrum is then proportional to (Andersen and Beyer 2015):

$$
N(w) \propto \frac{1}{g(w)} \exp \left(-\int_{w_{0}}^{w} \frac{\mu(\omega)}{g(\omega)} \mathrm{d} \omega\right)
$$

Inserting $\mu(w)$ and $g(w)$ gives $N(w) \propto w^{-n-a}$ for $w \gg w_{0}$ where $a=\mu(w) w /$ $g(w)$ is the ratio between mortality and specific growth; here $a \approx 0.3$ and $n=3 / 4$. In the representation with biomass in log-width size groups the spectrum becomes $N(w) w^{2} \propto w^{0.95}$. This corresponds well with the results from simulations of the full dynamic model (the slope of the thin dashed line in Figure 5a).

Emergent density dependent regulation is evident from plots of feeding level and mortality losses (Fig. A2-3). The type of density dependent regulation depends on the resource productivity: low productivity results in density dependence manifested as competition leading to reduced growth rates; high productivity results in density dependent cannibalism. The magnitude of density dependent regulation depends on asymptotic size: the larger the species, the more density dependent regulation is needed to maintain the population at equilibrium levels.

The body size where the dominant density dependent regulation occurs depends on the size of the ecosystem: a small ecosystem leads to late density dependent bottlenecks (Fig. A2) while a large system leads to early density dependent bottlenecks (Fig. A3). From the plots showing emergent density dependent regulation 
we have selected the four cases for a species with asymptotic size $W_{\infty}=1 \mathrm{~kg}$ used in the main text (top and bottom panels in the middle column of Fig A2 and A3). See Tabel A2 for parameter values and Fig. 5 for size spectra and growth curves. 
Table A1 Governing equations

\begin{tabular}{|c|c|c|}
\hline Description & Equation & No. \\
\hline \multicolumn{3}{|l|}{ Encounter } \\
\hline Size preference for prey & $\phi\left(\frac{w_{p}}{w}\right)=\exp \left[-\left(\ln \left(\frac{w}{w_{p} \beta}\right)\right)^{2} /\left(2 \sigma^{2}\right)\right]$ & M1 \\
\hline Encountered food & $E_{e}(w)=\gamma w^{q} \int_{0}^{w}\left(N\left(w_{p}\right)+N_{R}\left(w_{p}\right)\right) w_{p} \phi\left(\frac{w_{p}}{w}\right) \mathrm{d} w_{p}$ & M2 \\
\hline Feeding level & $f(w)=\frac{E_{e}(w)}{E_{e}(w)+h w^{n}}$ & M3 \\
\hline Consumption & $C(w)=h w^{n} f(w)$ & M4 \\
\hline \multicolumn{3}{|l|}{ Growth and reproduction } \\
\hline Available energy & $E_{a}(w)=\alpha C(w)-k_{r} w^{n}-k_{a} w$ & M5 \\
\hline Growth & $g(w)=(1-\psi(w)) E_{a}(w)$ & M6 \\
\hline Reproduction & $R(w)=\epsilon \psi(w) E_{a}(w) /\left(2 w_{0}\right)$ & M7 \\
\hline Maturation $^{(1)}$ & $\psi(w)=H\left(\frac{w}{\eta_{m} W_{\infty}}\right) \frac{1-\epsilon_{a}}{\left(w / W_{\infty}\right)^{n-1}-\epsilon_{a}}$ & M8a \\
\hline $\begin{array}{l}\text { Switching function } \\
\text { Boundary condition }\end{array}$ & $H(z)=\left(1+z^{-10}\right)^{-1}$ & M8b \\
\hline Standard & $g\left(w_{0}\right) N\left(w_{0}\right)=\int_{w_{0}}^{W_{\infty}} R N(w) \mathrm{d} w$ & M9a \\
\hline Stock-recruitment rel. & $g\left(w_{0}\right) N\left(w_{0}\right)=R_{\max } \frac{\int R N(w) \mathrm{d} w}{\int R N(w) \mathrm{d} w+R_{\max }}$ & M9b \\
\hline \multicolumn{3}{|l|}{ Mortality } \\
\hline Background predation & $\mu_{0}(w)=\alpha_{p} w^{n-1}$ & M10 \\
\hline Predation by species & $\begin{aligned} \mu_{p}\left(w_{p}\right)=\int_{w_{0}}^{W_{\infty}} & \phi\left(\frac{w_{p}}{w}\right)(1 \\
& -f(w)) \gamma w^{q} N(w) \max \left(1,\left(w / w_{+}\right)^{-s}\right) \mathrm{d} w\end{aligned}$ & M11 \\
\hline Fishing, trawl selectivity & $\mu_{F}(w)=F H\left(\frac{w}{w_{F}}\right)$ & M12a \\
\hline $\begin{array}{l}\text { Fishing, balanced } \\
\text { selectivity } \\
\text { Resource dynamics }\end{array}$ & $\mu_{F}(w)=F H\left(\frac{w}{w_{F}}\right)\left(\frac{w}{w_{\text {ref }}}\right)^{-1 / 4}$ & M12b \\
\hline Population dynamics & $\frac{\mathrm{d} N_{R}(w)}{\mathrm{d} t}=r_{R}(w)\left(K_{R}(w)-N_{R}(w)\right)-\mu_{p}(w) N_{R}(w)$ & M13 \\
\hline Carrying capacity & $K_{R}(w)=\kappa w^{\lambda}$ & M14 \\
\hline Growth rate & $r_{R}(w)=r_{0} w^{n-1}$ & M15 \\
\hline
\end{tabular}


Table A2. Parameters

\begin{tabular}{|c|c|c|}
\hline \multirow{2}{*}{\multicolumn{3}{|c|}{ Symbol and Value }} \\
\hline & & \\
\hline Preferred predator-prey mass ratio & $\beta=100$ & \\
\hline Width of pred.-prey mass ratio & $\sigma=1.3$ & \\
\hline Factor for clearance rate & $\gamma=6.6 \times 10^{-10} \mathrm{~g}^{-q} / \mathrm{yr}$ & 1,6 \\
\hline Exponent for clearance rate & $q=0.8$ & \\
\hline Factor for maximum consumption rate & $h=18.6 \mathrm{~g}^{1-n} / \mathrm{yr}$ & 2 \\
\hline $\begin{array}{l}\text { Exponent for maximum consumption } \\
\text { rate }\end{array}$ & $n=3 / 4$ & \\
\hline \multicolumn{3}{|l|}{ Growth and reproduction } \\
\hline Assimilation efficiency & $\alpha=0.6$ & \\
\hline Factor for standard metabolism & $k_{r}=f_{c} \alpha h$ with $f_{c}=0.2$ & \\
\hline Factor for activity & $k_{a}=\epsilon_{a} \alpha h\left(f_{0}-f_{c}\right) W_{\infty}^{n-1}$ with $f_{0}=0.6$ & 3 \\
\hline Fraction for activity & $\epsilon_{a}=0.8$ & 3 \\
\hline Offspring size & $w_{0}=0.001 \mathrm{~g}$ & \\
\hline Reproduction efficiency & $\epsilon=0.1$ & \\
\hline $\begin{array}{l}\text { Size of maturation relative to } \\
\text { asymptotic size }\end{array}$ & $\eta_{m}=0.25$ & \\
\hline \multicolumn{3}{|l|}{ Mortality } \\
\hline Mortality factor & $\alpha_{p}=1.56 \mathrm{~g}^{0.25} / \mathrm{yr}$ & 4 \\
\hline $\begin{array}{l}\text { Reference size for balanced harvesting } \\
\text { Resource dynamics }\end{array}$ & $w_{\text {ref }}=1 \mathrm{~g}$ & 6 \\
\hline Factor for carrying capacity & $\kappa=10^{10} \mathrm{~g}^{-1-\lambda}$ & 1,6 \\
\hline Exponent for carrying capacity & $\lambda=-2-q+n=-2.05$ & 5 \\
\hline Growth rate of resource & $r_{0}=$ variable $\left(\mathrm{g}^{0.25} \mathrm{yr}^{-1}\right)($ see table 4$)$ & \\
\hline \multicolumn{3}{|l|}{ Stock-recruitment relation } \\
\hline Maximum recruitment & $R_{\max }=1 \mathrm{yr}^{-1}$ & 6 \\
\hline \multicolumn{3}{|l|}{ Spatial dynamics } \\
\hline Speed of cohort spreading & $s=1$ & \\
\hline Size where cohort fills habitat & $w_{+}=$variable $(\mathrm{g})$ & \\
\hline \multicolumn{2}{|r|}{ viduals feeding on the resource at carrying capa } & \\
\hline \multicolumn{3}{|l|}{$\begin{array}{l}\text { 2) Set such that individuals feec } \\
\text { Andersen and Bever (2015). }\end{array}$} \\
\hline \multicolumn{3}{|l|}{ 3) Set } \\
\hline 4) Corresponding to a physiological $n$ & tality of 0.35 as in Andersen and Beyer (2015). & \\
\hline $\begin{array}{l}\text { 5) Will lead to a constant feeding leve } \\
\text { Beyer 2006). }\end{array}$ & vhen feeding at the carrying capacity (Andersen & \\
\hline 6) As all biomasses are scaled, the val & of this parameter is not important to the results & \\
\hline
\end{tabular}




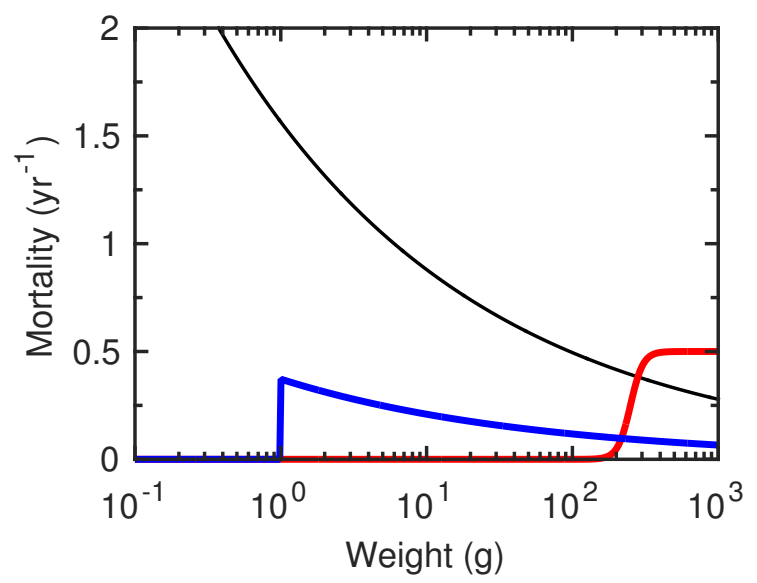

Figure A1. Mortality from natural causes (black) and from fishing. Red: trawl selectivity selecting only mature individuals with a fishing mortality which results in the maximum sustainable yield (here $0.5 \mathrm{yr}^{-1}$ ). Blue: balanced selection, targeting all sizes larger than $1 \mathrm{~g}$. 

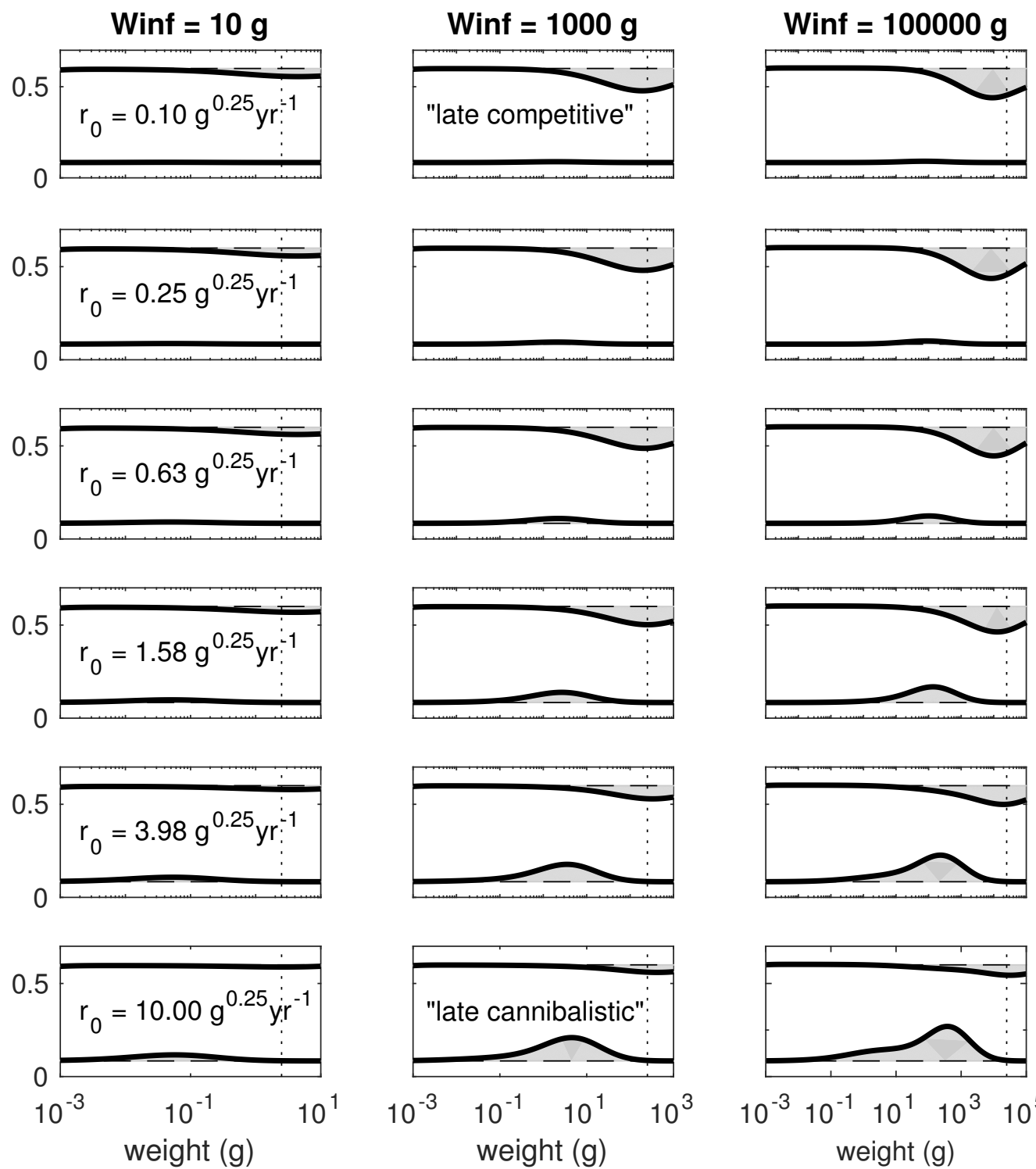

Figure A2. Biomass production and losses for species with three asymptotic sizes (columns) across a range of resource productivities (rows) in a small habitat where $w_{+}=w_{0}$ (egg size). Upper lines in each panel show the feeding level $f(w)$; lower lines show losses to mortality $l(w)$ with dashed lines indicating the predictions in the absence of density-dependent regulation. The grey areas indicate density-dependent regulation. Notice how density dependence changes from being driven by changes in biomass production due to resource depletion at low productivity to being driven by cannibalism at high productivity. Vertical dotted lines indicates size at maturation. Notice also how the strength of density dependent regulation (the size of the grey areas) increases with asymptotic size (left to right). 

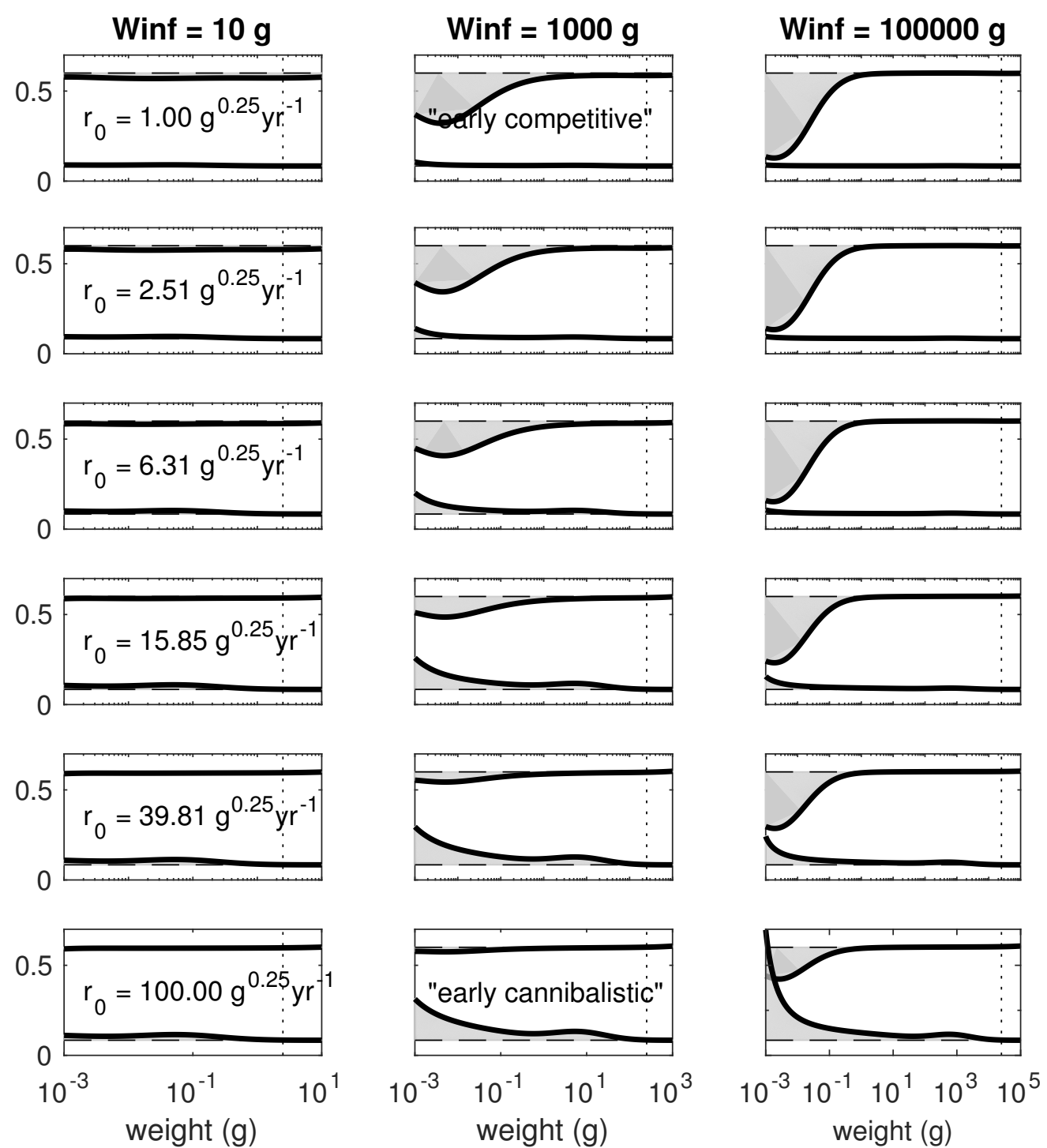

Figure A3. As Fig. A2 but in a large habitat $\left(s=1\right.$ and $\left.w_{+}=0.1 W_{\infty}\right)$. Compared to Fig. A2, the larger size means that density dependent regulation changes from late in life to early in life. Effects of productivity and asymptotic size are as in Fig. A2. 


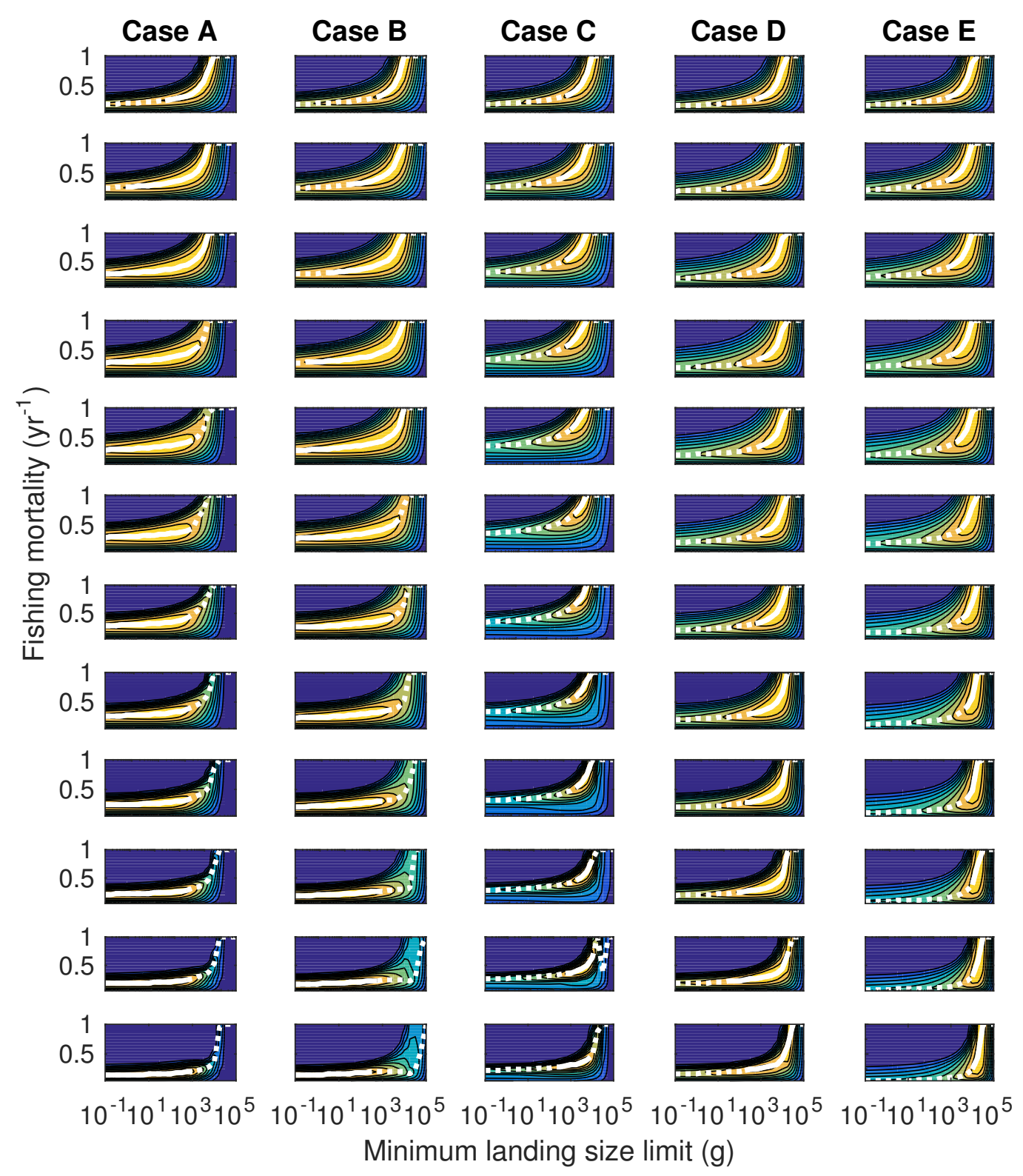

Figure A4. Yield surfaces as function of landing size limit and fishing mortality, corresponding to Fig. 5 in the main text. Rows: asymptotic size (top: $10 \mathrm{~g}$; bottom: $100 \mathrm{~kg}$ ); Cases in columns: A: early competitive; B: early cannibalistic; C: late competitive; D: late cannibalistic; E: stock-recruitment. 

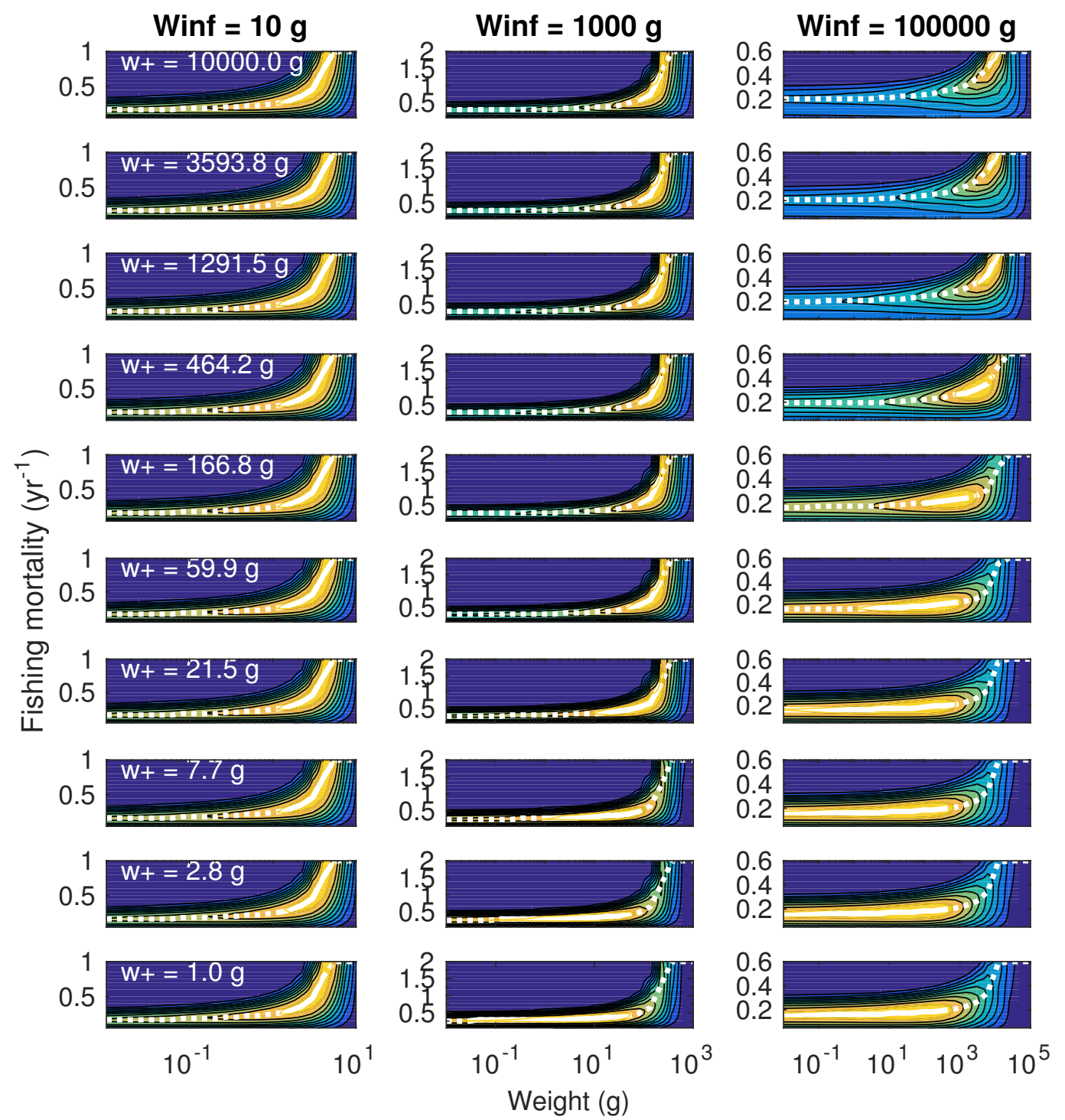

Figure A5. Yield surfaces as function of mesh size and fishing mortality used to draw figure 7B. Rows: system size (larger on top); columns: asymptotic size equal $10 \mathrm{~g}, 1 \mathrm{~kg}$ and $100 \mathrm{~kg} . r_{0}=1 \mathrm{~g}^{0.25} \mathrm{yr}^{-1}$. 


\section{Appendix B: Analysis of spatial spreading}

The spatial spreading of five marine fish stocks were analysed to provide examples of the process and to estimate the two model parameters, spreading speed $s$ and weight at maximum spreading $w_{+}$.

\section{Data}

Two datasets were compiled, one for demersal species and one for pelagic species.

Demersal species were analysed from standardised scientific bottom trawl surveys conducted annually in the North Sea in July-September 1991-2014 (ICES 2013). Catch weights, length distributions and otoliths (for age reading) were sampled for the demersal species Atlantic cod (Gadus morhua, Gadidae) and European plaice (Pleuronectes platessa, Pleuronectidae). Age disaggregated catch rates were calculated by $1^{\circ}$ longitude $\mathrm{x} 0.5^{\circ}$ latitude rectangles by the DATRAS system at the International Council for the Exploration of the Sea (ICES) data centre and downloaded from the ICES repository (http://datras.ices.dk). Methods and calculations are documented in ICES (2013).

Pelagic species were analysed from standardized acoustic surveys conducted annually in July in the North Sea from 2003-2014. Acoustic data were collected along predefined transects and pelagic trawling used to sample species- and length-distributions of the observed schools. Individual fish weights were recorded and otoliths were analysed to acquire information on age and stock origin. Abundance of herring (Clupea harengus, Clupeidae) and sprat (Sprattus sprattus, Clupeidae) by $1^{\circ}$ longitude x $0.5^{\circ}$ latitude rectangles were calculated from acoustic backscattering energy and length distributions (Simmonds and Maclennan 2005, ICES 2015). Total abundance by age, stock and rectangle was then calculated by the FishFrame system as described in Jansen and Degel (2006).

\section{Analysis}

The distribution of each species is represented as the number of individuals (sprat, herring) or Catch per Unit Effort (CPUE) (cod, plaice) by weight group. Sprat, the two stocks of herring and cod are recorded by age (Figure B1-4), while plaice (Figure 2, main text, and Figure B5) is recorded by length-class. Conversion from age to weight was done using the weight-keys, while conversion from length to weight for plaice was done using the equation $w=$ $a L^{b}$, with parameters $a=0.0093 \mathrm{~g} \mathrm{~cm}^{-1}$ and $b=3.03$ (Fishbase: Froese and Pauly, 2013).

The occupied habitat was defined as the number of ICES squares and presented as a fraction of the maximum number of squares occupied by the entire population. Peripheral observations (rectangles that contained less than $5 \%$ of the distribution) were excluded from the analysis. To give a rough estimation of $s$, the function $\log 10$ (fraction of habitat) $=\log 10$ (weight) $\cdot s+c$ was applied using $\mathrm{R}$ version 3.03. The function was fitted to the points that representing the initial dispersal until the habitat is occupied. Since a minimum of two points for 
$w<w_{+}$really is required and, using cod as an example, age 1 is in reality around age $1 \frac{1}{2}$ covering a considerable body-size range so our $w_{+}$is overestimated for this reason alone and similarly, $\mathrm{s}$ is underestimated. We acknowledge the pitfalls of subjectively choosing a series of points to describe $s$, but do so here to illustrate the effect conceptually.

All the species presented reach the size of maximum distribution $\left(w_{+}\right)$quite fast (Table B1). 4 out of 5 stocks reach $w_{+}$between Age 0 and Age 1, indicating that for stocks in the North Sea $w_{+} \approx$ size at maturation. The estimated values of $s$ range between 0.3 and 1.6 (mean $=0.84$ ), but they are very uncertain due to the lack of resolution between year 0 and year 1 .

The analysis clearly illustrate that a cohort of individuals disperse in space during ontogeny. The quantitative estimations of $w_{+}$and in particular $s$ should at best be considered indicative. Averaging the data over many years causes limitations to the analysis of $s$, since it therefore does not follow a single cohort, as required by the theory, but rather the average cohort. Further, the data here could be a mixture of different sub-populations and be dominated by large single cohorts. A key limitation is the lack of resolution of weight classes and low catchability for age 0 individuals. The only stock where sufficiently resolved data were available are plaice (shown in the main text Fig. 2). Improving the estimation of $s$ requires targeted cohort and size-specific studies.

\section{Acknowledgements}

We wish to thank the survey scientists and sampling technicians from England, Denmark, France, Germany, Netherlands, Norway and Scotland who collected the data analyzed in the present study.

Table B1: analysed stocks

\begin{tabular}{lrrr} 
Stock & $w_{\text {mat }}(\mathrm{g})^{*}$ & $W_{\infty}(\mathrm{g})^{*}$ & $w_{+}(\mathrm{g})$ \\
\hline Herring (47d3) & 112 & 334 & 65 \\
Herring (Vian) & - & 334 & 105 \\
Sprat & 8 & 33 & 10 \\
Cod & 925 & 23000 & 250 \\
Plaice & 284 & 1250 & $85-155$ \\
\hline
\end{tabular}

* (Fishbase: Froese and Pauly, 2013). 

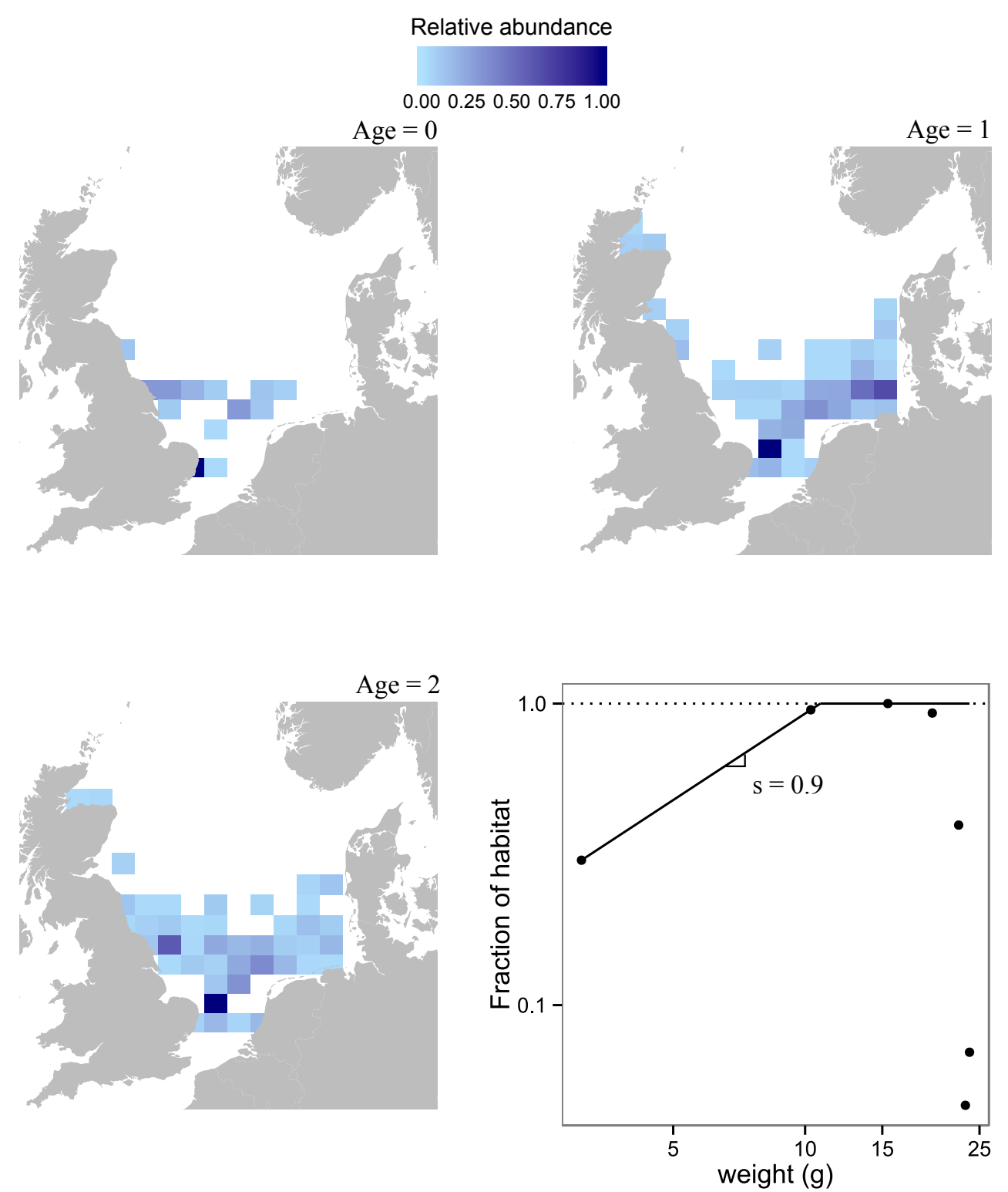

Figure B1: Distribution of sprat in the North Sea. $w_{+} \approx 10 \mathrm{~g}$. Intensity of the contour indicates relative abundance of the size class. 

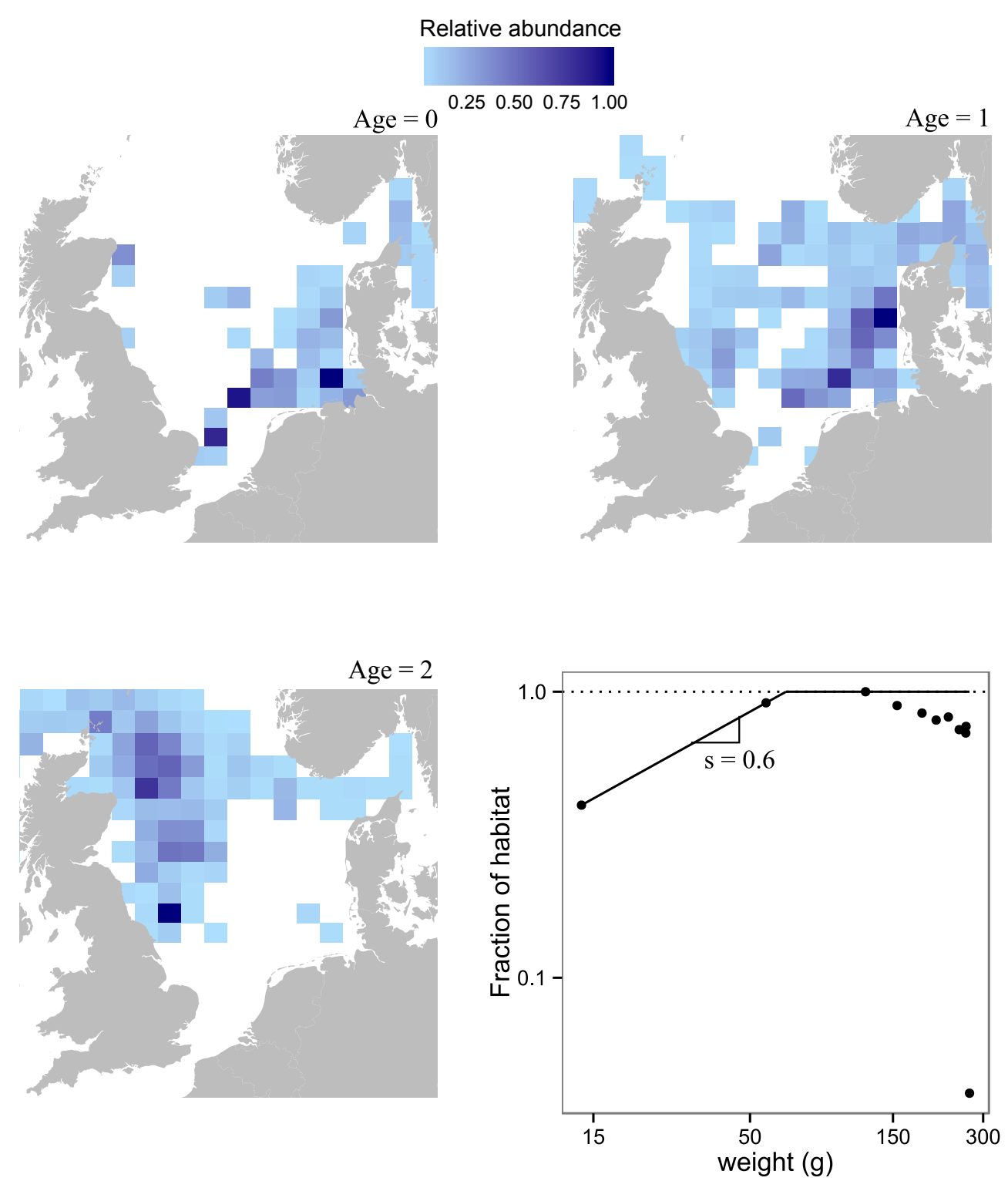

Figure B2: Age specific distribution of herring, ICES stock-47d3. The total distribution seems limited by the survey, rather than the species distribution from age 1 and onwards. $w_{+} \approx 65$ g. Intensity of the color represents relative abundance of each size class. 

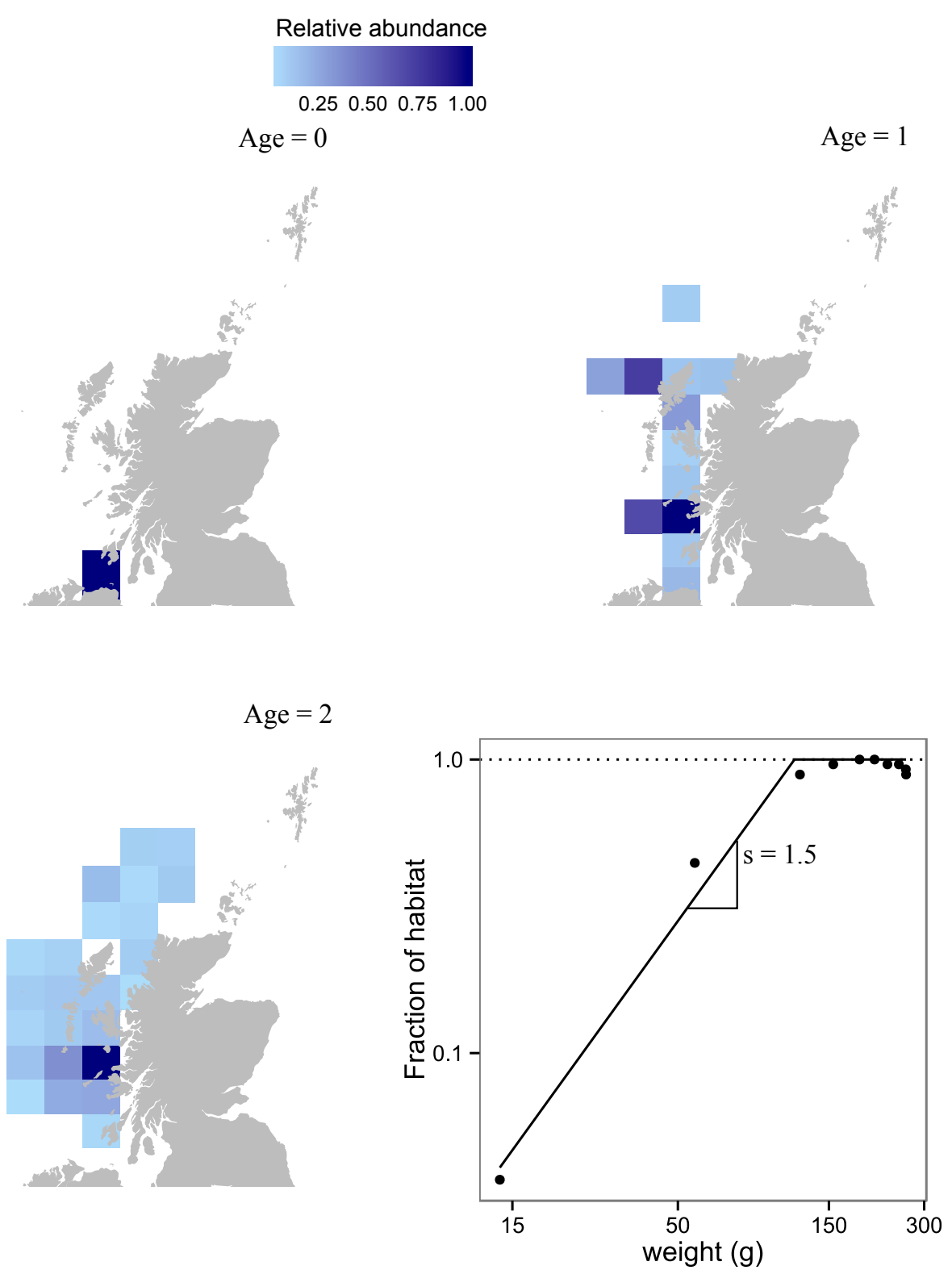

Figure B3: Distribution of VIaN-Herring West of the British Isles. Intensity of the color represents relative abundance. $w_{+} \approx 115 \mathrm{~g}$. 

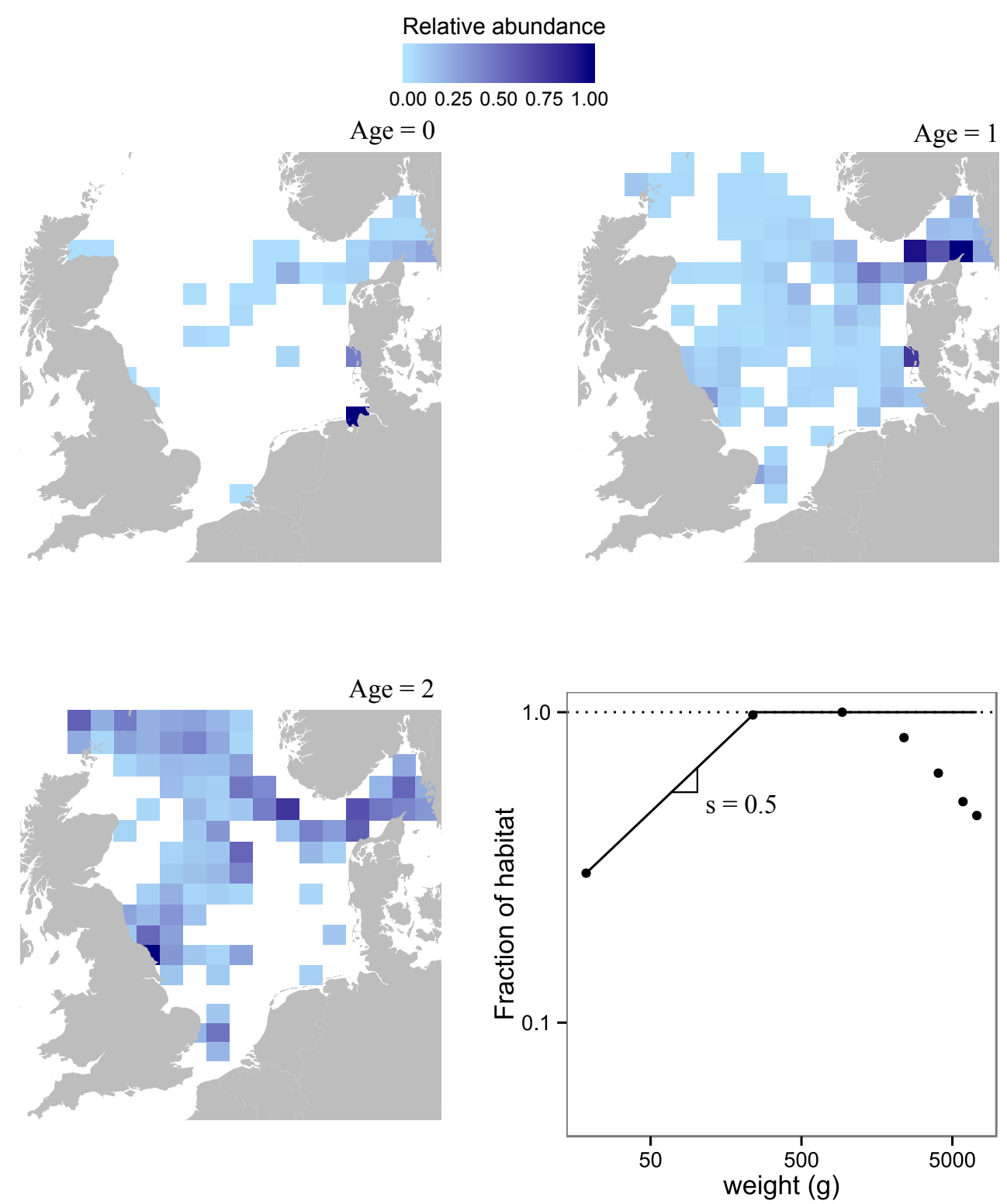

Figure B4: The distribution of cod in the North Sea from different weight classes. Intensity of color is relative abundance. $w_{+} \approx 250 \mathrm{~g}$. 


\section{Appendix C: theoretical arguments for the value of $s$}

The simple model of cohort dispersal (Eq. 1) should be considered a first attempt of capturing the essence of how a cohort of fish spreads out in space as a function of body-size. At size $w_{+}$the cohort can be considered for all practical purposes to occupy its entire habitat, i.e. we assume $A(w)=1$ for $w>w_{+}$. We consider $w_{+}$a system specific parameter and expect it to increase with the size of the system (habitat) so in general it will be larger for marine fish than in a small lake. Here we are interested in the speed of dispersal of a cohort as a function of body size, i.e., the magnitude of the exponent $s$. We develop three simplified arguments for $s$ based on 1) a diffusion approximation, 2) an argument about direct expansion and 3) an argument about constant density dependent regulation.

\section{Diffusion approximation:}

Assume that the fish perform a random walk with diffusivity $D(t)$ where the diffusivity changes with time as the individuals grow. In two dimensions we can interpret the area as the expected variance of the random walk:

$$
A(t)=4 \int_{0}^{t} D(s) \mathrm{d} s .
$$

This can be rewritten as a function of body size by a change of variables:

$$
A(w) \propto \int_{w_{0}}^{w} D(\omega)\left(\frac{\mathrm{d} \omega}{\mathrm{d} t}\right)^{-1} \mathrm{~d} \omega
$$

The growth rate of juvenile fish is roughly $\mathrm{d} w / \mathrm{dt} \propto w^{0.75}$ (West et al. 2001). The diffusivity is a result of random movements with velocity $v$ and decorrelation length $l$. Writing both as a function of weight, i.e. velocity as $w^{p}$ and decorrelation length proportional to the length of the fish $l \propto w^{1 / 3}$ leads to $D(w) \propto w^{p+1 / 3}$. Inserting in the integral and assuming $w \gg w_{0}$ gives

$$
A(w) \propto w^{0.58+p} .
$$

The swimming speed of fish can generally be considered proportional to bodylength to the power of 0.45 (Kiørboe 2011) that is $p=0.15$ for length $\propto w^{1 / 3}$. This gives $s \approx 0.73$.

\section{Direct expansion}

Consider the cohort being homogeneously distributed within a circle of radius $R$ that increases in proportion to the swimming speed then $\mathrm{d} R / \mathrm{d} t \propto w^{p}$. Dividing by $\mathrm{d} w / \mathrm{d} t \propto w^{3 / 4}$ implies $\mathrm{d} R / \mathrm{d} w \propto w^{p-3 / 4}$ so $R \propto w^{p+1 / 4}$. Hence the area $A(w)$ becomes proportional to $w^{2 p+1 / 2}$, so $s=2 p+1 / 2$.

Using the scaling of swimming speed from the argument above, i.e., $p=0.15$, gives $s \approx 0.80$. However, in the viscous regime, i.e. for body-length smaller than ca. $7 \mathrm{~cm}$, speed scales with body-length to the power of 0.79 (Kiørboe, 2011) or $p=0.26$ for isometric growth leading to $s \approx 1.29$. 


\section{Constant density dependence}

Consider that the cohort spreads such that the population density of conspecifics within the area remain constant relative to the total population density of organisms with the same size. This implies that the cohort regulates its area such that density dependent effects are independent of size, i.e. $s \approx 0.90$. This idea has similarities to the "member/vagrant" hypothesis for density dependent dynamics among fish in the ocean (Sinclair and Iles 1989) or the idea of an ideal free distribution (MacCall 1990).

Each argument gives a value of $s$ just around the critical value of $s=0.90$. For the numerical simulations leading to early life density dependence we have therefore used a value larger than 0.90 to generate early density dependent regulation, but only slightly larger, i.e. $s=1$. 


\section{Appendix D: influence of size-selection pattern}

All previous analyses have been performed with a trawl type size selection where individuals larger than the size limit are equally targeted by fishing. Using a "balanced" (Garcia et al. 2012; Jacobsen et al. 2014) selection pattern where smaller individuals are targeted more heavily than larger ones (Fig. A1) gives fairly similar results to the trawl selection (Fig. D1; compare with Fig. 3). One difference is that the peak of the yield maximum is more pronounced than with the trawl selectivity. Balanced fishing should therefore be at least as selective, or even more selective, than trawl selectivity to maximize yield. Balanced fishing might give higher yield than trawl selectivity if density dependent regulation happens early, but the effect is modest ( $<10 \%$; Fig. D1b). Our result is in apparent contrast to recent simulations with a similar model which predicted up to double the yield with balanced than with trawl selectivity (Law et al. 2015), however these results were a product of comparison between balanced and trawl selectivity with different mesh sizes. If this difference is accounted for, the results are similar. Our result does agree with the ideas of balanced harvesting that a higher yield may be produced if juveniles are targeted, however we show that this only occurs if density dependent regulation happens late in life. Within a single-species context balanced harvesting does therefore not provide any increases in yield. The potential beneficial aspects of balanced harvesting must therefore lie in its use as an ecosystem harvesting strategy (Jacobsen et al. 2014, Law et al. 2016). 

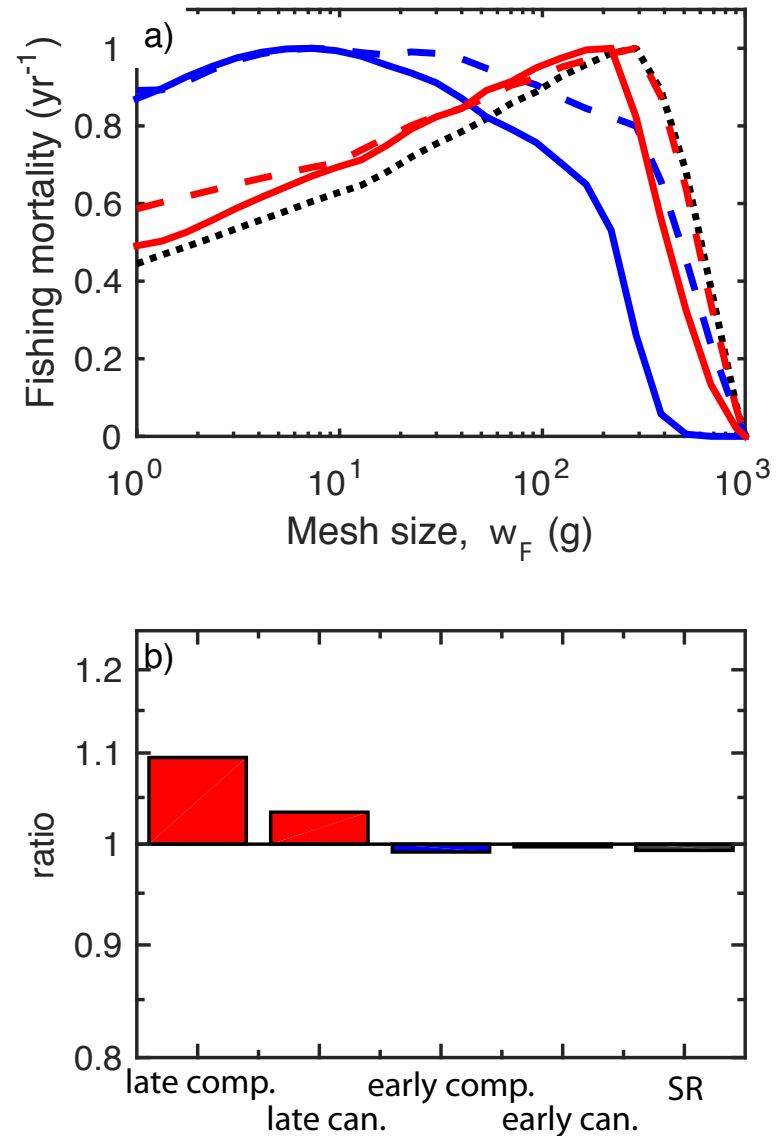

Fig. D1. Yields from fishing with a "balanced" size selectivity (Fig. A1). A) yield vs. size limit as in Fig. 3. B) The ratio between the maximum yields from balanced and trawl-like size selectivity. Same line types as in Fig. 6. 


\section{References}

Andersen, K. H., and J. E. Beyer. 2006. Asymptotic size determines species abundance in the marine size spectrum. The American Naturalist 168:5461.

Andersen, K. H., and J. E. Beyer. 2015. Size structure, not metabolic scaling rules, determines fisheries reference points. Fish and Fisheries 16:1-22.

Froese, R., and D. Pauly. 2013. FishBase. www.fishbase.org.

Garcia, S. M., J. Kolding, J. Rice, M. J. Rochet, S. Zhou, T. Arimoto, J. E. Beyer, L. Borges, A. Bundy, D. Dunn, and others. 2012. Reconsidering the consequences of selective fisheries. Science 335:1045-1047.

Hartvig, M., K. H. Andersen, and J. E. Beyer. 2011. Food web framework for sizestructured populations. Journal of Theoretical Biology 272:113-122.

ICES. 2013. Manual for the International Bottom Trawl Surveys. Page 83Series of ICES Survey Protocols. SISP 1-IBTS IX.

ICES. 2015. Manual for International Pelagic Surveys (IPS). v.1.00. Page Report of the Working Group of International Pelagic Surveys (WGIPS). ICES C.M.2015/SSGEISST:01.

Jacobsen, N. S., H. Gislason, and K. H. Andersen. 2014. The consequences of balanced harvesting of fish communities. Proceedings of the Royal Society B 281:20132701.

Jansen, T., and H. Degel. 2006. FishFrame 4.3 User Manual.

Kiørboe, T. 2011. How zooplankton feed: mechanisms, traits and trade-offs. Biological reviews of the Cambridge Philosophical Society 86:311-39.

Law, R., J. Kolding, and M. J. Plank. 2015. Squaring the circle: reconciling fishing and conservation of aquatic ecosystems. Fish and Fisheries 16:160-174.

Law, R., M. J. Plank, and J. Kolding. 2016. Balanced exploitation and coexistence of interacting, size-structured, fish species. Fish and Fisheries 17:281-302.

MacCall, A. D. 1990. Dynamic geography of marine fish populations. University of Washington press.

Sheldon, R., A. Prakash, and W. H. Sutcliffe. 1972. The size distribution of particles in the ocean. Limnology and Oceanography 17:327-340.

Simmonds, J. E., and D. N. Maclennan. 2005. Fisheries acoustics - Theory and practice. Page Reviews in Fish Biology and Fisheries.

Sinclair, M., and T. D. Iles. 1989. Population regulation and speciation in the oceans. ICES J. Mar. Sci. 45:165-175.

West, G. B., J. H. Brown, and B. J. Enquist. 2001. A general model for ontogenetic growth. Nature 413:628-631. 